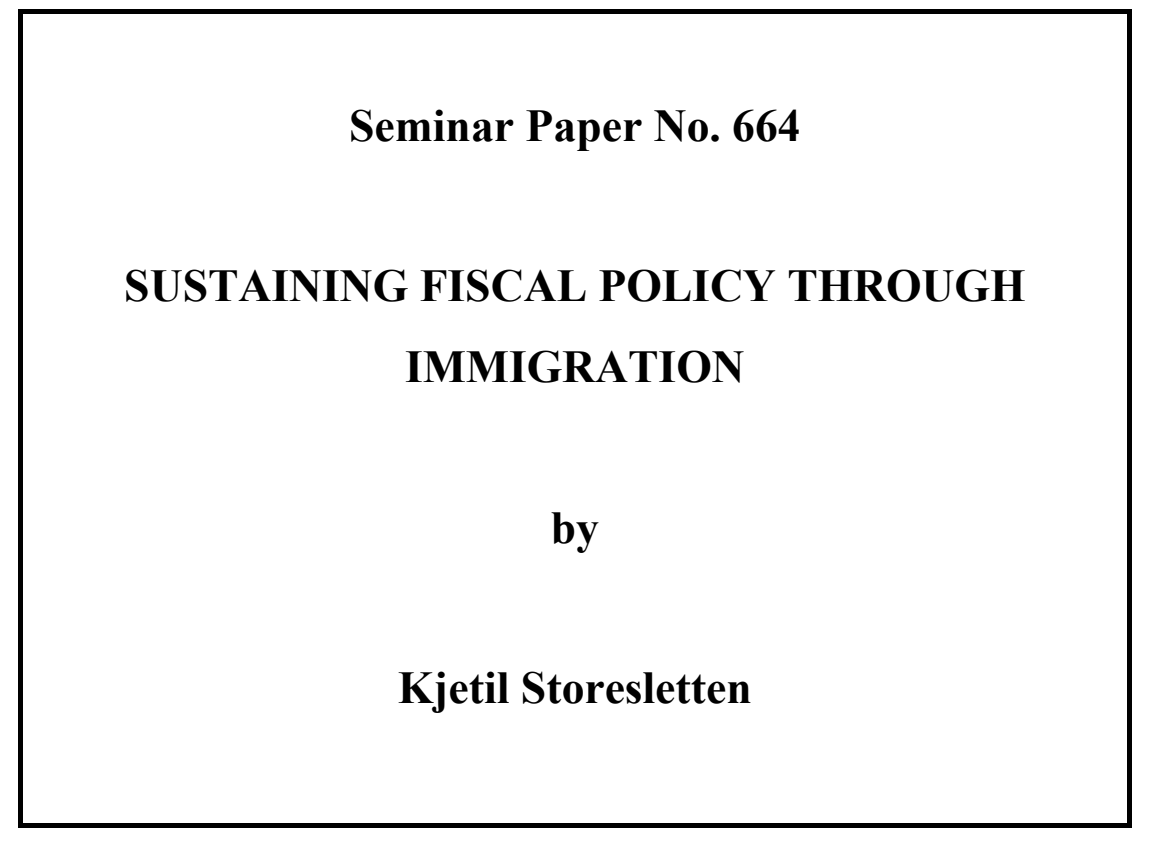

Kjetil Storesletten

INSTITUTE FOR INTERNATIONAL ECONOMIC STUDIES Stockholm University 
Seminar Paper No. 664

\section{SUSTAINING FISCAL POLICY THROUGH IMMIGRATION \\ by \\ Kjetil Storesletten}

Papers in the seminar series are also published on internet in Adobe Acrobat (PDF) format.

Download from http://www.iies.su.se/

Seminar Papers are preliminary material circulated to stimulate discussion and critical comment.

September 1998

Institute for International Economic Studies

S-106 91 Stockholm

Sweden 


\title{
Sustaining Fiscal Policy Through Immigration
}

\author{
Kjetil Storesletten*
}

Revised version, September 4, 1998

First version, February 27, 1997

*Institute for International Economic Studies, Stockholm University, 10691 Stockholm, Sweden. kjetil.storesletten@iies.su.se. I owe special thanks to José Víctor Ríos-Rull and Finn E. Kydland for their valuable guidance and suggestions. I am also grateful for comments and help from Michele Boldrin, Christina Lönnblad, Dennis Epple, John Hassler, Alan Head, Stéphane Pallage, Torsten Persson, Seth Sanders, and two anonymous referees. All errors are my own. 


\begin{abstract}
This paper explores the fiscal implications of immigration to the US, and argues that immigration policy should be viewed as a vital part of fiscal policy. In particular, a case is made that skills and age at the time of arrival are of great importance for the cost-benefit calculation of new immigrants. Using a calibrated general equilibrium overlapping generations model, which explicitly accounts for key differences between immigrants and natives, Social Security and the demographic transition, I investigate if an immigration policy reform alone could resolve the fiscal problems associated with the ageing of the baby boom generation. I find that such policies exist and are characterized by increased inflows of working-age highand medium-skilled immigrants. One particular feasible policy involves admitting 1.6 million 40-44 year old high-skilled immigrants annually, compared to a total of 1.1 million today. In contrast, an income tax hike of $4.4 \%$ points would be required if future fiscal problems were to be solved by a once and for all tax reform. To further illuminate the fiscal impact of immigration, I compute the net government gain, in present value terms, of admitting one additional immigrant. This figure varies considerably with age and skills and reaches a maximum of seven times GNP per capita for high-skilled 40-44 year old immigrants. In contrast, new immigrants represent, on average, a small net gain of $\$ 7,400$, or 0.3 times GNP per capita.
\end{abstract}




\section{Introduction}

Fiscal effects of immigration has been a central issue in the heated public debate on immigration in the US. The impact of immigration on public coffers is potentially very large, since the flow of immigrants is so strong - about 1.1 million per year - and the newcomers are quite different from Americans. In particular, immigrants are much younger, have a more widespread skill distribution and, on average, have higher fertility than natives.

The age and skills of new immigrants are of special importance since public expenditures are highly age dependent (schools, Social Security, etc.) and individual earnings, and thus tax contributions, are closely tied to skills and age. The US population is ageing and future Social Security payments represent a significant liability for the government (see e.g. Aaron, Bosworth, \& Burtless (1989)). Combining this future liability with a shrinking tax base and current budget deficits, a future with higher taxes and fewer public services seems inevitable. However, since most new immigrants are young - more than $40 \%$ of the new legal immigrants who came during 1980-1988 were between 20 and 34 years old - immigration might alleviate some of the future fiscal burden.

The aim of this paper is to quantify the fiscal impact of immigration and, in particular, explore the role of age and skills of new immigrants. To this end, I compute the net government gain, in present value terms, of admitting one additional immigrant, conditional on skills and age at the time of immigration. Moreover, I explore if immigration policy alone could be used as an instrument to balance the budget and avoid fiscal reform altogether.

Immigration can be expected to affect the government budget through several channels. An inflow of working-age immigrants should initially increase tax revenues per capita and reduce government debt and government expenditures per capita. When immigrants retire, the impact on tax revenues and expenditures will presumably be reversed. Moreover, the government budget is affected through changes in prices due to a rise in the labor-capital ratio (assuming capital does not flow into the country in response to immigration). A higher labor to capital ratio typically increases interest rates and decreases wages. Higher interest rates, in turn, raise the cost of servicing the public debt, and a fall in wages is likely to reduce tax revenues, since most taxes are collected from labor under the US tax system. Quantifying the relative strengths of these effects requires a general equilibrium analysis in an overlapping generations model.

The framework is a dynamic equilibrium model of population transition, closely related to Auerbach \& Kotlikoff (1987). The population distribution adjusts in response to ageing and

changes in immigration and fertility. Fertility follows an exogenous process, while mortality is taken to be constant. Immigration is given by an immigration policy determining the age and skill structure and the annual inflow of new immigrants. Natives and immigrants in the model economy differ in age, skills, and fertility. Immigrants are, in addition, differentiated 
by age at the time of immigration and by their legal status. Fiscal policy is exogenously given and consists of a payroll tax, an income tax, a transfer system that explicitly incorporates Social Security, and an age-specific rule for public consumption. The role of the government is to jointly determine income taxes and an immigration policy such that the exogenous spending policy is feasible, meaning that the present value of government assets and tax revenues equals the present value of future expenditures.

I show that immigration policies which would remove the need for a future fiscal reform do exist and are characterized by increased inflows of working-age high- and medium-skilled immigrants. Moreover, I compute the smallest increase in annual immigration required to balance the budget, given that the government is free to choose the distribution of age and skills of new immigrants, while restricted to keeping the current tax and spending policies unchanged. This minimum change involves increasing annual immigration from $0.44 \%$ to $0.62 \%$ of the population, or about 1.6 million, provided all new immigrants are high-skilled and 40-44 years old. Admitting adult immigrants but excluding their children may not be politically feasible, however. If immigrants were instead admitted in family units, the minimum number of immigrants required would increase to $1.08 \%$ of the population annually - assuming the head of the family to be high-skilled and 45-49 years old. While admitting 1.6 million immigrants annually might seem like a considerable change of policy, it is illuminating to contrast this to an alternative fiscal reform: income taxes would have to increase by $4.4 \%$ points if one opted for changing taxes instead of immigration policy or government expenditures. Thus, it seems sensible to consider at least marginal immigration policy reforms as part of a larger fiscal reform package.

These findings are driven by the following results: Under the current fiscal policy and the immigration policy outlined above, the discounted value of future tax receipts less government expenditures associated with an additional immigrant varies considerably with age and skills and reaches a maximum of $\$ 177,000$, or seven times GNP per capita, for high-skilled immigrants who arrive when they are 40-44 years old. This includes the cost of future descendants. The average NPV of representative high-, medium-, and low-skilled legal immigrants are found to be $\$ 96,000,-\$ 2,000$, and $-\$ 36,000$, respectively, which yields a net average government gain of admitting new legal immigrants of a mere $\$ 7,400$. In comparison, the NPV of a newborn native is $-\$ 88,000$.

All age profiles of NPV for new immigrants are hump-shaped and peak between 35 and 44 years old. The timing of the peak is robust to several changes in the model setup, due to a basic trade-off between a longer remaining working life on the one hand, and a smaller number of new children on the other. Abstracting from the cost of future children would increase the average discounted gain by $\$ 20,000$ and make the age profiles peak earlier. If, alternatively, family migration is considered (immigrants bringing existing children when immigrating), the maximum NPV falls to $\$ 140,000$ per 42 year old high-skilled heads of 
household.

Return migration - immigrants returning to their respective source countries - is explicitly accounted for and, indeed, the rate of emigration matter for immigrants' discounted contribution to public coffers the way one might expect: the NPV of new immigrants increases in the return migration rate for most age-skill groups except for 5-49 year old high-skilled immigrants and 15-44 year old medium-skilled immigrants.

I also propose a method for incorporating general equilibrium effects when evaluating the NPV contribution of new immigrants, and find the price effects to be quantitatively important: the maximum NPV, for instance, decreases with $31 \%$ once price effects are taken into consideration.

To the extent that one is willing to consider using the immigration policy for enriching public coffers, the paper offers several immediate policy implications. Primarily, the analysis suggests which groups of immigrants to target, if the aim is to maximize the public coffer contribution per immigrant. For instance, the Canadian "point system" for allocating visas to prospective immigrants favors skilled immigrants in the age group 20-40. My calculations suggest, however, that focusing on high-skilled immigrants in the age bracket 20-49 would make more sense if maximizing public gain is the objective, as the NPV of high-skilled immigrants between 40 and 49 far exceeds that of 20-24 year old high-skilled immigrants.

Moreover, the results indicate that the discounted government cost of new illegal immigrants can be as large as $\$ 54,000$ per immigrant, compared with $\$ 36,000$ for legal low-skilled immigrants. If curbing illegal immigration is infeasible, these results suggest that converting young illegal immigrants to legal ones, along the lines of the 1986 IRCA legislation, is beneficial, provided the flow of illegal immigrants is not affected by this amnesty policy.

Finally, I find that return migration decreases the discounted contribution of high-skilled immigrants under 50. Thus, policies which lower the return migration probability for this group might improve public finances. Straightforward examples of such reforms would be to make the rules for allocating visas and green cards to immigrants already working in the US less strict, and to automatically grant green cards to foreign students upon graduation.

It is important to stress, however, that cash-maximizing immigration policy reforms should be seen as complements to the more traditional humanitarian immigration policy objectives. Improved public finances is precisely what widens the scope for pursuing, say, liberal refugee policies.

Despite the strong implications of immigration for public finance, surprisingly few studies address the cost-benefit aspect of immigration. One vein of the literature has focused on computing net government surplus in a particular year of all immigrants currently residing in the host country. Borjas (1994), Huddle (1994) and Passel (1994) have made such calcu- 
lations for the US. This approach has several serious shortcomings. First, an annual surplus or deficit cannot be interpreted as a net government gain on immigration since current expenditures and revenues will change as a function of the age structure. Second, payments occurring later in the life of an immigrant should be discounted more heavily than earlier ones. Thus, simply adding all revenues and expenditures assign too much weight on old age payment streams.

Some of these problems are partly alleviated in Simon (1984) and Akbari (1989). In a particular year, they compute tax revenues and government expenditures directly associated with different immigration cohorts. These are used as a stand-in for a time profile of net benefits which, in turn, is discounted to get a crude measure of the "net public gain". In addition to the severe inference problems associated with a constantly changing age profile of new immigrants, these studies ignore population dynamics, Social Security and the general equilibrium interaction between immigrants and an ageing population. Descendants of immigrants are also omitted from the analysis.

The dynamic fiscal policy literature addresses the above population dynamics and general equilibrium issues by explicitly accounting for demographics and fiscal policy in a dynamic equilibrium framework, see e.g. Auerbach \& Kotlikoff (1987). Some studies, e.g. Auerbach, Kotlikoff, Hagemann, \& Nicoletti (1989), include immigration as part of an exogenous demographic process, but immigrants are not distinguished from natives, and they make no attempts to explore the impact of the immigration policy.

To my knowledge, Bonin, Raffelhüschen, \& Walliser (1997) is the only alternative study which includes dynamic effects of immigration. They perform a partial equilibrium generational accounting exercise for Germany, and confirm a positive fiscal impact of high-skilled young immigrants. In their setting immigration policy reform cannot shore up the need for a future fiscal reform in Germany, however.

The paper then proceeds as follows. The model economy and the competitive equilibrium are defined in Section 2 and Section 3, and Section 4 describes the numerical solution. The parameterization of the economy is discussed in Section 5, and the results are reported in Section 6. Section 7 concludes.

\section{The model}

\subsection{Population process and heterogeneity}

The economy is populated by agents who live a maximum of $I$ periods. Agents differ in age, skills, legal status (native, legal immigrant, or illegal immigrant), and, if an immigrant, the age at the time of immigration. The "type" of an agent is denoted by $(i, q, l, m)$, where $i$ 
is age, $q$ is skill, $l$ is legal status, and $m \in M$ is the age at the time of immigration (where natives have $m=1$ ). The key difference between natives and legal immigrants in the model is in terms of labor productivity and fertility. Note that the productivity of immigrants is strongly influenced by education and age at time of immigration, see e.g. Friedberg (1993).

The immigrants' skills (or education) take on three values: $q \in\{1,2,3\}$, or low-skilled, medium-skilled and high-skilled. Skills are exogenous and do not change during an agent's lifetime. For simplicity, the skills of natives are assumed to be homogenous (conditional on age), so $q \equiv 0$ for natives.

The labels of legal status are $l=0$ for natives, $l=1$ for legal immigrants, and $l=2$ for illegal immigrants. Distinguishing immigrants by legal status is important because illegal immigrants might be very different from legal immigrants with respect to their impact on public coffers. Moreover, illegal immigration constitutes a substantial share of the migration to the US (Fix \& Passel (1994)).

Children of immigrants, born after their parents immigrated, are considered as natives. As natives are homogenous, this implicitly assumes the skills of second-generation immigrants to be independent of the skills of their parents. Following Lee (1974) and Ríos-Rull (1992), the birth process is modeled as $\mu_{1,0,0,1, t}=\sum_{i, q, l, m} \phi_{i, q, l, m} \mu_{i, q, l, m, t}+y_{t}$, where $\mu_{i, q, l, m, t}$ is the measure of type $(i, q, l, m)$ agents in period $t, \mu_{1,0,0,1, t}$ is the number of newborn natives at time $t, \phi_{i, q, l, m}$ are type-specific fertility rates averaged over time, and $y_{t}$ is a deterministic process. Note that there is no uncertainty about future fertility. Agents do face longevity uncertainty, however. Conditional on being alive at age $i$, the probability of surviving to age $i+1$ for a type $(i, q, l, m)$ agent is $s_{i, q, l, m}$.

A certain immigration policy is chosen by the government and determines the number and age composition of new legal immigrants as a function $\psi$ of the state of the economy. I assume that the government cannot alter the flow of illegal immigrants. There are numerous ways of specifying the possible immigration policies. I focus on a very simple type of policies where the inflow of each age and skill group is some fixed fraction of the size of the population.

Empirical studies have documented that as many as $18-20 \%$ of the new immigrants return to their respective home countries within ten years after their first arrival to the US (see Borjas \& Bratsberg (1996), Jasso \& Rosenzweig (1982), and Warren \& Peck (1980)). As these authors point out, the process of return migration might have complex interactions with economic performance in the host country. To keep the analysis transparent, however, I abstract from this possibility and simply assume that the probability of return migration, $\eta_{j}$, only depends on the spell in the host country (where $j$ stands for years since immigration). To further simplify the problem, I assume that the agents who return migrate will face the same transfers, taxes and returns to their skills in their home countries as they would have faced in the host country (so immigrants do not have to take the event of return migration 
into consideration).

\subsection{Preferences, technology, government, and market structure}

Agents derive utility from a standard consumption good and leisure. Preferences are time separable. The instantaneous utility takes the form $u(c, 1-n)$, where $c$ is the current consumption, $n$ is the time spent working in the market, and $u(., 1-n)$ and $u(c,$.$) are$ strictly concave and increasing. Agents younger than age $\zeta$ are defined as children. Children do not work and consume only the transfers they get from the government. Furthermore, agents do not care about their children and have no bequest motives, although they will end up leaving accidental bequests. At a certain age, all agents retire. Immigrants and natives have identical preferences. A type $m$ agent maximizes her expected lifetime utility, given by

$$
\max _{\left\{c_{t}, n_{t}\right\}} \mathrm{E} \sum_{t=\max \{m, \zeta\}}^{I} \beta^{t} u\left(c_{t}, n_{t}\right)=\max _{\left\{c_{t}, n_{t}\right\}} \sum_{t=\max \{m, \zeta\}}^{I} \beta^{t} \pi_{i, q, l, m} u\left(c_{t}, n_{t}\right)
$$

subject to the intertemporal budget constraints. $\pi_{i, q, l, m}$ is the unconditional probability for an agent of type $m$ of being alive at age $i$ (so $\pi_{m, q, l, m}=1$ and $\left.\pi_{i, q, l, m} \equiv \prod_{j=m}^{i-1} s_{j, q, l, m}\right)$. Agents get zero utility when dead.

Output in period $t$ is given by a standard constant return to scale production function $z_{t} f\left(K_{t}, N_{t}\right)$ with aggregate labor $N_{t}$ and capital $K_{t}$ as inputs. The level of the technological progress, $z_{t}$, is growing at a deterministic rate. Output is used for consumption and investment in new capital. Labor productivity of an agent is measured in equally productive efficiency units, which implies that native and immigrant labor are perfect substitutes. Aggregate labor input in period $t, N_{t}$, is the sum of efficiency units supplied by agents, i.e.

$N_{t}=\sum_{i, q, l, m} e_{i, q, l, m} n_{i, q, l, m, t} \mu_{i, q, l, m, t}$, where $n_{i, q, l, m, t}$ is time spent working, $e_{i, q, l, m}$ is the number of labor efficiency units for agents of type $(i, q, l, m)$, and, again, $\mu_{i, q, l, m, t}$ is the measure of type $(i, q, l, m)$ agents in period $t$. Accordingly, the only role of skills is to increase the number of efficiency units. Firms rent labor and capital on spot markets at a given wage rate $W_{t}$ and a net rental rate $R_{t}$ and the firms solve

$$
\max _{K, N}\left\{z_{t} f(K, N)-\left(R_{t}+\delta\right) K-W_{t} N\right\}
$$

where $\delta$ is the depreciation rate for capital.

Fiscal policy is given exogenously and consists of a tax rule, a public spending rule, and a transfer rule that includes Social Security and other government transfer programs. The tax rule specifies a constant payroll tax rate $\tau_{S}$, and a constant tax rate $\tau$ on capital and labor income (net of payrolls tax). Natives and legal immigrants are taxed at the same rates. 
Illegal immigrants differ from their legal counterparts in that they pay no taxes and receive no government transfers. They are assumed, however, to incur public consumption at the same rate as their legal counterparts. Taxation of transfers will be dealt with below.

Public consumption is given by a rule determining government purchases of goods and services as a function of population and time:

$$
G_{t} \equiv(1+\Gamma)^{t} \sum_{i, q, l, m} g_{i} \mu_{i, q, l, m, t}
$$

where $g_{i}$ is government consumption per agent of age $i$ in period zero and $\Gamma$ is the rate of growth in GNP per capita in steady state. Conditioning the incidence of public consumption on age is important since large components of government purchases of goods and services are age dependent (e.g. the schooling system). A possible link between government consumption and skills and legal status is more ambiguous, however, so I have chosen to stick to the simpler rule. The specification of $G_{t}$ in (3) implies that growth in total government consumption are driven by demographic changes and long run growth in GNP per capita. Since the immigration policy specifies immigration as a fraction of the population, the population structure will converge to a steady state over time, which implies that the long-run growth rate of GNP will eventually coincide with $\Gamma$, the long-run growth rate in $G$. In the calibrated version of the economy, the growth rate of GNP will be lower than $\Gamma$ during the first periods, however. I will return to this in Section 6.

The government pays Social Security benefits consisting of old age insurance (OAI), survivors' insurance (SI), disability insurance (DI), and Medicare (consisting of hospital insurance (HI), and supplementary medical insurance (SMI)). OAI benefits are paid to retired agents only. An individual's OAI transfer is a function $h($.$) of her average indexed monthly$ earnings (AIME) during her time in the work force. I model the SI, DI and HI benefits as age-specific lump sum transfers $\xi_{i}$. The SMI program currently receives large subsidies from the federal government, and the subsidy part of SMI benefits is modeled as part of $\xi_{i}$. All other government transfer programs, including welfare payments, unemployment insurance, etc., are lumped together as part of $\xi_{i}$.

This specification abstracts from possible differences between immigrants and natives in the utilization of government transfer programs. Borjas \& Hilton (1996) document that immigrants have a higher participation rate in welfare programs than natives. Fix, Passel, \& Zimmermann (1996) argue that these differences are explained by the higher welfare program participation rate among refugees and retired immigrants (who, presumably, do not qualify for Social Security benefits). My focus, however, is on labor migrants: working-age legal immigrants who will most likely qualify for Social Security when old. Moreover, my measure of $\xi_{i}$ encompasses all government transfers (net of $\mathrm{OAI}$ ), including programs where natives may well have a higher participation rate, like unemployment insurance or the SI part of 
Social Security. Canada, where labor immigrants are explicitly targeted, has a lower welfare participation rate among immigrants than among natives (Baker \& Benjamin (1995)).

Agents qualify for full Social Security benefits after having contributed for ten years, and residence in the US while retired is not a requirement for collecting benefits. Let $\hat{\mu}_{i, q, 1, m, t}$ denote the number of living return migrated legal immigrants of type $(i, q, m)$ who qualify for full Social Security benefits, let $\hat{\xi}_{i}$ be their lump sum transfers, and assume that only a fraction $\varkappa$ of these actually collect their benefits. Social Security benefits are partly taxable above a certain floor, and the function $\vartheta($.$) returns the part of benefits that is subject to$ income taxation. The aggregate Social Security benefits and other government transfers in period $t$ can then be computed as

$$
\begin{aligned}
T_{t} \equiv & \sum_{l=0}^{1} \sum_{i, q, m}\left\{\mu_{i, q, l, m, t}\left((1+\Gamma)^{t} \xi_{i}+h\left(d_{i, q, l, m, t}\right)\right)+\right. \\
& \left.+\varkappa \hat{\mu}_{i, q, l, m, t}\left((1+\Gamma)^{t} \hat{\xi}_{i}+h\left(d_{i, q, l, m, t}\right)\right)\right\}
\end{aligned}
$$

where $d_{i, q, l, m, t}$ is the AIME of an agent $(i, q, l, m)$ in period $t$. The total tax revenues are given by

$$
\begin{aligned}
\text { Revenues }_{t} \equiv & \left(1-\left(1-\tau_{S} / 2\right)\left(1-\tau-\tau_{S} / 2\right)\right) W_{t} \hat{N}_{t}+\tau R_{t} \hat{A}_{t}+ \\
& +\tau \sum_{l=0}^{1} \sum_{i, q, m} \vartheta\left((1+\Gamma)^{t} \xi_{i}+h\left(d_{i, q, l, m, t}\right)\right) \mu_{i, q, l, m, t}
\end{aligned}
$$

where $\hat{N}_{t}$ and $\hat{A}_{t}$ are aggregate labor input and private financial wealth of natives and legal immigrants, respectively, (so $\hat{N}_{t}=\sum_{l=0}^{1} \sum_{i, q, m} e_{i, q, l, m} n_{i, q, l, m, t} \mu_{i, q, l, m, t}$ ). Benefits paid to return migrated immigrants are not subject to taxation and are therefore absent in (5). Note that the employer part of Social Security contributions is tax deductible.

Budget deficits are financed by increases in government bonds $B_{t}$. Bonds are held by private agents and evolve according to

$$
B_{t+1}=B_{t}\left(1+R_{t}\right)-\text { Revenues }_{t}+T_{t}+G_{t} .
$$

There are no annuities markets in the economy, so the agents face the risk of dying with positive wealth. Each period accidental bequests are donated to newborn natives in a lump 
sum $x_{t}$, which is given by

$$
\begin{aligned}
x_{t} \equiv & \sum_{l=1}^{2} \sum_{q, m} \sum_{i=m}^{I}\left(1-\eta_{i-m+1}\right)\left(1-s_{i, q, l, m}\right) a_{i, q, l, m, t} \frac{\mu_{i-1, q, l, m, t-1}}{\mu_{1,0,0,1, t}}+ \\
& +\sum_{i=2}^{I}\left(1-s_{i, 0,0,1}\right) a_{i, 0,0,1, t} \frac{\mu_{i, 0,0,1, t-1}}{\mu_{1,0,0,1, t}}
\end{aligned}
$$

where $a_{i, q, l, m, t}$ and $a_{i+1, q, l, m, t+1}$ are the agent's wealth in period $t$ and $t+1$, respectively. The first term in the numerator is total accidental bequests left by natives, and the second term is accidental bequests left by immigrants who did not migrate back before dying. The wealth of a one year old native is $x_{t}$, while immigrants are assumed to bring no wealth with them when they first immigrate. The only portfolio constraint is that agents of age $I$ (who will die for sure) cannot leave negative bequests. The budget constraint for agent $(i, q, l, m)$, where $l<2$, can then be written recursively as

$$
\begin{aligned}
& c_{i, q, l, m, t}+a_{i+1, q, l, m, t+1} \leq W_{t} e_{i, q, l, m} n_{i, q, l, m, t}\left(1-\tau_{S} / 2\right)\left(1-\tau-\tau_{S} / 2\right)+ \\
& +(1+\Gamma)^{t} \xi_{i}+h\left(d_{i, q, l, m, t}\right)-\tau \vartheta\left((1+\Gamma)^{t} \xi_{i}+h\left(d_{i, q, l, m, t}\right)\right)+\left(1+(1-\tau) R_{t}\right) a_{i, q, l, m, t} .
\end{aligned}
$$

In contrast, the recursive budget constraint for an illegal immigrant $(i, q, 2, m)$ is

$$
c_{i, q, 2, m, t}+a_{i+1, q, 2, m, t+1} \leq W_{t} e_{i, q, 2, m} n_{i, q, 2, m, t}+\left(1+R_{t}\right) a_{i, q, 2, m, t} .
$$

Finally, note that agents who emigrate bring their savings, and that total remittances at the end of period $t$ are

$$
R M_{t} \equiv \sum_{i, q, l, m} a_{i+1, q, l, m, t+1} \eta_{i-m+1} \mu_{i, q, l, m, t} .
$$

This model specification abstracts from nonrival public goods and congestion effects (scarce public capital diluted by new immigrants), as I see the parsimonious constant return to scale economy as a conservative benchmark for the fiscal effects of immigrants. I will, however, consider the sensitivity of the results to the inclusion of a nonrival public good. One feature of the existing model which does capture a public good element of immigration is that the per capita government debt falls as immigration increases. As the model abstracts from government-owned physical capital, parts of government consumption, $g_{i}$, can be interpreted as a stand-in for replenishing government capital per agent of age $i$. Thus, a potentially increased pressure for public investments due to increased immigration is captured in the model, as government consumption rises one for one with new immigrants. 


\section{Equilibrium}

Given initial conditions for the debt $B_{0}$, the error term of the fertility process $y_{0}$, and the distributions of assets $a_{0}$, past average earnings $d_{0}$ and population $\mu_{0}$ and $\hat{\mu}_{0}$, an equilibrium is defined as a sequence

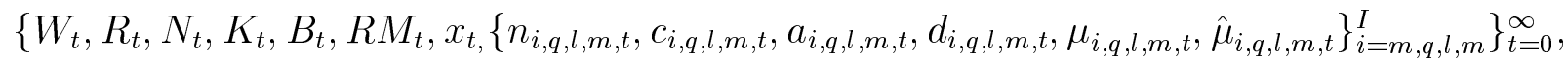
a tax rate $\tau$, and an immigration policy rule $\psi$, such that the following holds

a) The rental prices for labor and savings, $W_{t}$ and $R_{t}$, clear the markets for capital and labor in period $t$, i.e. prices equal marginal productivities:

$$
\begin{aligned}
& \frac{\partial z_{t} f\left(K_{t}, N_{t}\right)}{\partial K}=W_{t} \\
& \frac{\partial z_{t} f\left(K_{t}, N_{t}\right)}{\partial N}=R_{t}+\delta
\end{aligned}
$$

where $\delta$ is the rate of depreciation.

b) The goods market clears every period,

$$
z_{t} f\left(K_{t}, N_{t}\right)+(1-\delta) K_{t}=K_{t+1}+R M_{t}+G_{t}+\sum_{i, q, l, m} \mu_{i, q, l, m, t} c_{i, q, l, m, t}
$$

where $G_{t}$ and $R M_{t}$ satisfy (3) and (10).

c) For every $q, l, m$ and $t \geq 0$, the sequence

$\left\{c_{i, q, l, m, t+i-1}, n_{i, q, l, m, t+i-1}, a_{i, q, l, m, t+i-1}, d_{i, q, l, m, t+i-1}\right\}_{i=m}^{I}$ solves

$$
\max _{\left\{c_{j}, n_{j}\right\}} \sum_{j=\hat{m}}^{I} \beta^{j} \pi_{i, q, l, m} u\left(c_{j}, n_{j}\right)
$$

subject to (15)-(21) if the agent is not an illegal immigrant $(l<2)$, and subject to (22)-(27) if the agent is an illegal immigrant $(l=2)$, where

$$
\begin{aligned}
a_{m} & = \begin{cases}x_{t} & \text { if native } \\
0 & \text { otherwise }\end{cases} \\
a_{j+1} & \leq-c_{j}+W_{t+j-m} e_{i, q, l, m} n_{j}\left(1-\tau_{S} / 2\right)\left(1-\tau-\tau_{S} / 2\right)+ \\
+(1 & \left.+(1-\tau) R_{t+j-m}\right) a_{j}+(1+\Gamma)^{t} \xi_{j}+h\left(d_{j}\right)-\tau \vartheta\left((1+\Gamma)^{t} \xi_{j}+h\left(d_{j}\right)\right) \\
a_{I+1} & \geqslant 0 \\
d_{0} & =0 \\
d_{j+1} & =d_{j}+e_{i, q, l, m} n_{j}
\end{aligned}
$$




$$
\begin{aligned}
n_{j}=0 & \forall j \geq R \text { and } j<\zeta \\
c_{j}=\xi_{j} & \forall j<\zeta
\end{aligned}
$$

and

$$
\begin{aligned}
a_{m} & =0 \\
a_{j+1} & \leq W_{t+j-1} e_{i, q, 2, m} n_{j}+R_{t+j-m} a_{j}-c_{j} \quad \forall j \geq 1 \\
a_{I+1} & \geqslant 0 \\
d_{j} & =0 \quad \forall j \geq 1 \\
n_{j} & =0 \quad \forall j<\zeta \text { and } j<\text { retirement } \\
c_{j} & =0 \quad \forall j<\zeta .
\end{aligned}
$$

d) Bequests per newborn native, $x_{t}$, satisfy (7).

e) The government policy $(\psi, \nu)$ is feasible, in the sense that current government debt equals the net present value of future surplus:

$$
B_{0}=\sum_{t=0}^{\infty}\left\{\text { Revenues }_{t}-G_{t}-T_{t}\right\}\left(1+R_{0}\right) \Pi_{j=0}^{t} \frac{1}{1+R_{j}}
$$

where $G_{t}, T_{t}$, and Revenues ${ }_{t}$ are given by (3) to (5).

f) The sequence of government debt is generated by the government's short-term budget constraint (6).

g) Aggregate capital $K_{t}$ is a function of individual asset holdings and government debt:

$$
K_{t}=\sum_{i, q, l, m} \mu_{i, q, l, m, t} a_{i, q, l, m, t}-B_{t}
$$

h) The population sequences $\left\{\left\{\mu_{i, q, l, m, t}\right\}_{i=m, q, l, m}^{I}\right\}_{t=1}^{\infty}$ and $\left\{\left\{\hat{\mu}_{i, q, l, m, t}\right\}_{i=m, q, l, m}^{I}\right\}_{t=1}^{\infty}$ are generated by $\mu_{0}, \hat{\mu}_{0}, y_{0}, \psi$, and the mortality, fertility, and return migration processes.

\section{Numerical solution}

For a given set of initial conditions, the numerical problem is to find an immigration policy and an associated fixed point for the interest rate sequence such that the resulting allocations satisfy the equilibrium conditions. The model is solved by using a method related to the Auerbach \& Kotlikoff (1987) approach. In a nutshell, the idea is to iterate on the immigration policy and, for every iteration, solve for the equilibrium price sequence $\left\{R_{t}\right\}_{t=1}^{100}$, given initial 
conditions. Solving for the equilibrium price sequence $\left\{R_{t}\right\}_{t=1}^{100}$ is itself a fixed point problem which requires a series of iterations. A key assumption is that the economy is in steady state after a large number of periods, 100 in this case. ${ }^{1}$ More formally, the methodology is to

1. Choose an initial immigration policy $\psi$, i.e. an age and skill structure of new immigrants and an annual inflow of such immigrants as a fraction of the total population.

2. Compute the steady state interest rate $R_{\psi}^{*}$ associated with $\psi$. This involves solving numerically for a set of nonlinear equations in marginal utilities and the labor-capital ratio.

3. Compute the temporary equilibrium sequence $R(\psi) \equiv\left\{R_{\psi, t}\right\}_{t=1}^{100}$, defined as the equilibrium price sequence up to period 100 conditional on $\psi$, and an interest rate $R_{\psi}^{*}$ after period 100. This requires that equilibrium conditions $a$ )- $h$ ) are satisfied for every period $t \in\{1, \ldots, 100\}$. Solving for $R(\psi)$ involves a series of iterations in order to find a fixed point. A new guess of $R(\psi)$ is generated as an average of the previous guess, $R_{0}(\psi)$ say, and the price sequences implied by the decision rules that would prevail if $R_{0}(\psi)$ were the true equilibrium price sequence.

4. Check if quantities $\left\{\left\{c_{i, q, l, m, 100}, n_{i, q, l, m, 100}, d_{i, q, l, m, 100}\right\}_{i=m, q, l, m}^{I}, B_{100}\right\}$ equal their counterparts in the steady state associated with $\psi$. If so, an equilibrium is found. If not, change $\psi$ and return to 2 ).

\section{Parameterization of the model economy}

The model economy is calibrated to US data and Table 1 contains a listing of the key choices.

\subsection{Population parameters}

The length of a period in the model is taken to be five years. Each agent retires after period 13 and might live until period 18 (i.e. agents retire at 65 and die before 90 ). The mortality rates of natives and immigrants are assumed to be identical, fixed at the 1988 US levels. This implies a life expectancy of 77 years at birth. Since many immigrants originate from countries where tropical diseases are common, a case could be made for immigrants having higher mortality than natives. Shorter longevity would increase net government benefit from immigration so the equal mortality assumption is a conservative benchmark.

\footnotetext{
1 The economies converge well before the time horizon. After 20 periods, which correspond to 100 years, the annualized rate of return on capital in the benchmark immigration reform economy, is only 10 basispoints away from its steady state value, and the difference is smaller forever thereafter.
} 
Recall that the birth process is modeled as $\mu_{1,0,0,1, t}=\sum_{i, q, l, m} \phi_{i, q, l, m} \mu_{i, q, l, m, t}+y_{t}$. The agespecific average fertility rates $\phi_{i, 0,0,1}$ for natives are estimated by averaging over the 1960-89 time period. This implies a final total fertility rate of 2.23 , compared with 2.25 in the middle U.S. Bureau of the Census (1996) projections and 1.90 in the SSA middle projections (Bell (1997)). Storesletten (1995) estimates immigrant women's fertility using data from the 1990 and 1980 Census, and parameters $\phi_{i, q, l, m}$ are set accordingly. ${ }^{2}$ Lee (1974) found that the error term $y_{t}$ in the above birth process can be represented by an $\mathrm{AR}(2)$ process using US data from 1917 to 1972. This specification also fitted well for the 1960-90 period. The estimated coefficients are $\rho_{1}=1.28$ and $\rho_{2}=-0.65$. The standard deviation of the white noise in the regression is $0.15 \%$ of the population and $R^{2}$ is 0.86 . In the model, $y_{t}$ is assumed to follow a deterministic version of the estimated $\operatorname{AR}(2)$ process, with the 1992 values of the process as a starting point and shutting down future shocks.

Return migration appears to be quite high in the first years after immigration but then to decline sharply over time. For instance, Warren \& Peck (1980) find that $18 \%$ of the 196070 cohort of new immigrants and 5.2\% of the immigrants in 1960 had emigrated from the US by April 1, 1970. As an approximation of the return migration process, I assume that the unconditional return migration rate, $\eta_{t}$, is high during the first (five-year) period and constant thereafter. This emigration process apply to all immigrants. Using the $18 \%$ and $5.2 \%$ measurements of Warren \& Peck (1980) I find that $\eta_{1}=17.06 \%$ and $\eta_{t}=2.63 \%$ for all $t>=2 .^{3}$ The effect of this return migration process is illustrated in Figure 1.

$<$ Figure 1 about here $>$

All alternative immigration policies considered in this paper constitute increased inflows, relative to the status quo immigration policy, of one or several groups of legal immigrants. I measure the status quo immigration policy, unconditional on legal status, as the distribution of age and skills of immigrants enumerated in the 1990 Census who immigrated during

\footnotetext{
${ }^{2}$ The average five-year fertility rate between 1980 and 1990 for a group $(i, q, m)$ is estimated as $\hat{\phi}_{i, q, m} \equiv$ $\left(N C_{i+1, q, m, 1990}-N C_{i-1, q, m, 1980}\right) / 2$, where $N C_{i, q, m, t}$ is the number of children per female in group $(i, q, m)$ in year $t$, based on the 5\% PUMS files in the 1980 and 1990 Censuses. Recall that a time period is five years, so those who are $i$ periods old in 1980 are $i+2$ in 1990. Footnote 4 describes how areas of origin have been aggregated over. This approach implies that the fertility of high-skilled immigrants is about the same as that of high-skilled natives, while the fertility of medium- and low-skilled immigrants is about $20 \%$ higher than that of their native counterparts. Note that if native fertility were identified using the same approach, the estimate $\hat{\phi}_{i, 0,0,1}$ would deviate from the estimate $\phi_{i, 0,0,1}$ above (the average fertility over the 1960-89 time period, based on birth data). Accordingly, the estimates of immigrant fertility are amended to $\phi_{i, q, m}=\hat{\phi}_{i, q, m}-\hat{\phi}_{i, 0,0,1}+\phi_{i, 0,0,1}$. Legal status is not identified in the data, so I assume legal and illegal immigrants to have the same fertility, conditional on education, age, and age at time of immigration (thus, $\phi_{i, q, l, m}=\phi_{i, q, m}$ for $\left.l \in\{1,2\}\right)$.

${ }^{3}$ The return migration rates were computed in the following way. I assume that the low emigration rate applies for all immigrants present in 1960 , so $\left(1-\eta_{2}\right)\left(1-\eta_{3}\right)=1-0.052$ and $\eta_{2}=\eta_{3}=2.63 \%$. Moreover, if the total emigration rate during the first two periods (ten years) is $18 \%$ and a fraction $43 \%$ of the $1960-70$ cohorts of immigrants came in the first five-year period, then the equation $0.43 *\left(1-\eta_{1}\right)\left(1-\eta_{2}\right)+(1-0.43)\left(1-\eta_{1}\right)=$ $1-0.18$, identifies $\eta_{1}=17.06 \%$.
} 
1988-1990. This implies an annual inflow of immigrants of $0.44 \%$ of the population, or 1.1 million in the first period. The annual inflow of illegal immigrants currently constitute about 300,000 , or $0.12 \%$ of the population, (Fix \& Passel (1994)), and I assume this fraction to be constant over time. The distribution of skills among illegal immigrants will be dealt with below.

Note that the status quo population process implies a lower future dependency ratio (retirees

per worker), after 2010, than the standard alternative projections. For instance, the status quo case projects a maximum dependency ratio in 2035 of 0.315 (and 0.276 eventually), compared to 0.369 in 2035 (and 0.421 eventually) for the SSA projections. This discrepancy is due to higher mortality rates, more immigration, and higher fertility rates (after the year 2000), in the status quo population process than what is assumed in the SSA projections. Higher fertility rates will, as we shall see later, worsen the future fiscal burden, while higher mortality rates will alleviate the problems. Thus, in Section 6.9, I explore the sensitivity of the results to increased life expectancy.

\subsection{Preferences}

Preferences are standard. The instantaneous utility of any agent takes the form

$$
u\left(c_{t}, n_{t}\right)=\frac{\left(c_{t}^{\alpha}\left(1-n_{t}\right)^{1-\alpha}\right)^{1-\gamma}}{1-\gamma}
$$

This functional form implies a unit elasticity of substitution between consumption and leisure, which is motivated by fairly constant annual hours worked per household in the postwar period. The parameter $\alpha$ is set to 0.33. Ríos-Rull (1996) finds that this value yields life cycle patterns of agents' work effort consistent with US data. The inverse of the intertemporal elasticity of substitution, $\gamma$, is set at 4 since a period in the model is fairly long. The time preference parameter $\beta$ is set to 1.011 (annualized), based on estimates from Hurd (1989). Note that a more conventional discount rate is obtained when $\beta$ is multiplied with the survival probabilities.

\subsection{Technology and efficiency unit profiles}

Accounting for the differences in labor productivity between natives and immigrants is crucial when quantifying the effects of immigration. To this end, I use the 1990 Census and several issues of the INS Statistical Yearbook. The skills (or the education level) of immigrants are divided into three groups:

1. "low-skilled", high school or less, 
2. "medium-skilled", more than high school but less than a bachelor's degree,

3. "high-skilled", a bachelor's degree or more.

This yields three roughly equally sized skill groups: low-, medium-, and high-skilled adult immigrants account for $39.0 \%, 34.5 \%$, and 26.5\%, respectively. All illegal immigrants are assumed to be low-skilled. The distribution of skills among adolescent immigrants (0-19 years old) is assumed to be the same as for 25-29 year old new immigrants who immigrated before the age of 20 (of which 37\%, 45\%, and 18\% are low-, medium-, and high-skilled, respectively).

Estimates of the wage profiles of natives and immigrants (of different age, skill, and age at the time of immigration) are reported in Storesletten (1995). The estimation technique involves accounting for changes in national origin, gender, and the age of new immigrants over the 1950-90 period. ${ }^{4}$ Immigrants who came when they were, say, 27 years old, earn on average $2 \%$ less than natives over their remaining lifetime and those who immigrated when 37 years old earn $13 \%$ less. Borjas (1990) and others find the difference in earnings to be larger. Since the public finance implications of immigration are very sensitive to the labor income of natives, I also try an alternative earnings profile where immigrants earn $10 \%$ less than my estimates, roughly in line with the findings of Borjas (1990).

The technology is standard. I assume a standard Cobb-Douglas production function taking labor and capital as inputs, $Y_{t}=z_{t} K_{t}^{\theta} N_{t}^{1-\theta}$. Following Cooley \& Prescott (1995), the capital's share of income, $\theta$, and the (annualized) depreciation rate, $\delta$, are set to 0.4 and $4.8 \%$, respectively. The steady state growth rate in consumption per capita, $\Gamma$, is $1.5 \%$ (annualized), which equals the average annual US growth rate in GNP per capita over the last two decades. Accordingly, $z_{t}^{1-\theta}=(1+\Gamma)^{t}$.

\subsection{Government}

For calibrating several parameters of fiscal policy, I will use a "fiscal reform" economy where the current immigration policy is pursued and the budget is balanced through increasing taxes as a benchmark. Total federal, state and local tax revenues were $32.5 \%$ of GNP in

\footnotetext{
${ }^{4}$ Agents in the model differ in age, skills, legal status, and age at the time of immigration, so estimating efficiency units $e_{i, q, l, m}$ requires aggregation over sex, national origin, etc. The approach in Storesletten (1995) is to divide the $5 \% 1990$ Census sample into $15 \times 3 \times 12 \times 6 \times 2$ boxes (age, education, age at the time of immigration, area of origin, and sex), and to compute the average wage, $w_{i, q, m, a, s}$, for each box. The relative weights, $Q_{i, q, m, a, s}$, of type $(i, q, m, a, s)$ immigrants are then used for computing weighted average wage profiles for new immigrants: $\hat{e}_{i, q, m}=\sum_{a} \sum_{s} w_{i, q, m, a, s} \cdot Q_{i, q, m, a, s}$ Since legal status is not identified in the 1990 Census, I assume that no differences in wages between legal and illegal immigrants are left after controlling for education, area of origin, age, age at the time of immigration, and sex. Thus, $e_{i, q, l, m} \equiv \hat{e}_{i, q, m}$ for $l \in\{1,2\}$.
} 
1993. The income tax rate of the "status quo" fiscal policy is calibrated to $\tau=28.2 \%$, which would make total tax revenues amount to $32.5 \%$ of output in the first period of the fiscal reform economy (the equilibrium tax rate in the fiscal reform economy exceeds $28.2 \%$, which I will return to in Section 6). The payrolls tax, $\tau_{S}$, is set to $15.3 \%$ of labor income.

The benefit taxation function, $\vartheta($.$) , implies that benefits are taxed at three different marginal$ tax rates; $0,25 \%$, and $42.5 \%$ of the income tax rate $\tau$. In the US tax code the brackets depend on a joint function of benefits and other income. I have abstracted from this by letting $\vartheta($.$) depend on social security benefits only. The brackets where the marginal tax$ rates apply are computed from the tax code for an individual with income (less transfers) equal to the average income of retirees in the steady state of the fiscal reform economy. In this case, the brackets are 1.49 and 2.18 times GNP per capita (the highest marginal taxation of benefits in the actual tax code, 0.85 of $\tau$, cannot be reached for an agent with only average non-transfer income). The results are not very sensitive to the specification of $\vartheta($.$) , see Section 6.9$.

Recall that government consumption is modeled as $G_{t}=(1+\Gamma)^{t} \sum_{i, q, l, m} g_{i} \mu_{i, q, l, m, t}$ where $g_{i}$ is government purchases of goods and services for an agent of age $i$ in the base year. Using population data, the National Income and Product Accounts, and the Auerbach et al. (1989) estimates of age specific shares in non Social Security government expenditures, the levels of $g_{i}$ are computed to $20.6 \%, 11.3 \%$, and $19.5 \%$ of GNP per capita for the age groups $1-24$, 25-64, and 65+, respectively. This ensures a level of overall government consumption of $16.1 \%$ of GNP in the first period of the fiscal reform economy, the same as in 1993.

I assume all workers, except illegal immigrants, to be enrolled in Social Security. The Old Age Insurance (OAI) formula is a function $h($.$) of average indexed monthly earnings (AIME).$ $h$ is piecewise linear with two "bend points". The bend points are set to $20 \%$ and $122 \%$ of monthly GNP per capita based on data from the annual actuary reports. The replacement rates (i.e. slopes of $h$ ) within brackets 1, 2, and 3 are 90\%, 32\%, and 15\%, respectively. Recall that the benefits from survivors' insurance (SI), disability insurance (DI), and hospital insurance (HI), plus the subsidy part of supplementary medical insurance (SMI) are modeled as age dependent lump sum transfers $\xi_{i}$. I use unpublished data from the Social Security Administration to estimate the lump sum transfers.

All agents who have contributed to the Social Security system for more than ten years qualify for benefits according to US law, irrespective of whether they currently reside in the US or abroad. Using historical immigration figures and the calibrated return migration process, I find that 930,000 return migrants would have qualified for Social Security benefits in 1970. Warren \& Peck (1980) report that the Social Security administration in 1970 paid benefits to 230,000 return migrants (many countries have bilateral treaties with the US limiting the scope of collecting pension benefits from more than one country). Hence, I assume that $25 \%$, or $\varkappa$, of the return migrants claim the benefits they are entitled to. Moreover, return 
migrated agents do not participate in Medicare and the age profile of $\hat{\xi}_{i}$ is set accordingly.

So far I have dealt with the Social Security transfers. All other transfers on federal, state and local level (welfare, unemployment benefits, etc.), which added up to $7 \%$ of GNP in 1993, are distributed evenly as on all natives and legal immigrants as part of $\xi_{i}$. Aggregate government transfers in the first period, $T_{1}$, are then $14.4 \%$ of GNP in the fiscal reform economy, the same as the total federal, state and local transfers and subsidies in 1993.

\subsection{Initial conditions}

I use the 1992 distribution of natives as the initial condition for the population. The initial distribution of immigrants across age and skills is taken from the 1990 Census. Fix \& Passel (1994) report that about 3.2 million immigrants resided illegally in the US in 1992. Thus, 3.2 out of the initial 8 million low-skilled immigrants constitute the initial distribution of illegal immigrants.

The initial government debt, which consists of financial assets of the federal, state and local governments, is set to $50 \%$ of GNP in the fiscal reform economy.

The initial distribution of assets is the steady state distribution of assets scaled so that the initial capital to output ratio is 3.3 (in the fiscal reform economy). The steady state capital to output ratio in this economy is only 2.4 , and agents must hold $126 \%$ more wealth than in steady state to reach 3.3. ${ }^{5}$ To understand the impact of the initial capital stock, I also experiment with a lower initial capital to output ratio and a higher discount factor $\beta$.

\footnotetext{
${ }^{5}$ The $126 \%$ increase in individual wealth differs from 3.3/2.4 for two reasons. First, the initial population distribution differs from the steady state distribution, and second, the initial debt to output ratio, $50 \%$, exceeds the steady state debt to output ratio $(-39 \%)$. Thus, the initial wealth to output ratio is 3.8 $(=3.3+50 \%)$, which is higher than the steady state wealth to output ratio of 2.01 . Moreover, note that there is, at most, one stable steady state with $K_{t}>0$ for a given pair of immigration policy and fiscal policy. As attention has been restricted to constant tax rates and constant immigration rates over time, the initial conditions and immigration policy will determine the constant income tax rate $\tau$ (the lowest tax rate that satisfies the government's budget constraint (28). Equally, the initial conditions, fiscal policy, and a particular distribution of new immigrants pin down the required number of new immigrants and the future path of government debt. Indeed, if the tax rates or the immigration policy were allowed to vary over time, then the need for higher taxes or increased immigration during the demographic transition could be alleviated by for example aiming for a higher long-run debt to output ratio.
} 


\section{Findings}

\subsection{Fiscal reform}

Before turning to the immigration policy reform experiments I will describe the fiscal reform economy, where the current immigration policy is pursued and the budget is balanced through increasing taxes.

The equilibrium income tax rate $\tau$ in this economy is $32.6 \%, 4.4 \%$ points higher than the "status quo" tax rate of $28.2 \%$. Thus, a once and for all immediate tax hike of $4.4 \%$ points would preempt the need for any future fiscal reform associated with the demographic transition. Moreover, the government budget, including interest payments, would run surpluses from the first period.

Note that the rate of growth in GNP will be lower than $\Gamma$ during the initial periods. There are two reasons for this. First, the growth in the aggregate labor input will be sluggish as the population is ageing rapidly. Second, the initial wealth to output ratio (3.8) is very high compared with its steady state level (2.0), due to a large initial government debt and a big initial capital to output ratio. As agents reduce their wealth, the aggregate capital stock falls sharply. This fall is mirrored by an increase in the rate of return on capital (before tax), which rises from $6.8 \%$ in the first period to $10.0 \%$ in steady state, see Figure 2.

$<$ Figure 2 about here $>$

In the fiscal reform economy, Social Security benefits paid to return migrants constitute $0.04 \%$ of GNP, or 2.6 billion 1993 dollars annually, in the first period. The aggregate bequests in the first period amount to $3.1 \%$ of GNP.

The age profiles of consumption and work effort in this economy fit reasonably well with the data. Figure 3 plots average empirical age profiles of consumption per household member and annual hours. These compare favorably with the theoretical steady state profiles of consumption and work effort for natives, displayed in Figure 4. Differences worth pointing out are that the data exhibit a sharper decline in consumption after the age of 80 than does the model. Moreover, work effort after retirement (65) is by assumption zero in the model, compared to 249 hours in the data. Age profiles of consumption and work effort for the alternative immigration reform economies are quantitatively quite similar to those displayed for the fiscal reform economy.

$<$ Figures 3-4 about here $>$ 


\subsection{Immigration policy reform}

A central aim of the numerical experiments is to investigate if immigration policy reform alone can be used as an instrument to satisfy the government's long-run budget constraint (28), given that current tax and spending policies remain unchanged; that is, if the income tax rate $\tau$ is lowered to the "status quo" level of $28.2 \%$.

To this end, I explore a particular type of policies: let future immigration of each age and skill group of legal immigrants be some fraction of the population, fixed over time, and let the mix of country and gender of new immigrants be the same as for current immigrants. For each single age-skill group of new legal immigrants, I compute the smallest annual inflow of such immigrants, over and above the status quo flows of immigrants, that would balance the budget in the long run.

The first row in Table 2 summarizes the key results for the benchmark calibration. Within this class of policies, I find that the budget can be balanced with a sufficient inflow of any age group of high-skilled immigrants in the age group 20-54. So any mix of 20-54 year old high-skilled immigrants could constitute a feasible policy, and if the attention is restricted to immigrants under 20 or over 54 , there is no policy within this class that can balance the budget without increasing taxes or reducing government spending. For medium-skilled immigrants, the feasible age range is $25-49$, while no positive inflow of legal low-skilled immigrants can balance the government budget.

As can be seen from the first row of Table 2, 40-44 year old high-skilled immigrants is the group with the lowest fraction of new immigrants required to balance the budget: $0.617 \%$ annually, or about 1.6 million, compared to $.44 \%$ today. This policy will be referred to as the immigration reform policy and if pursued, the steady state population growth would be $0.9 \%$ annually. The equilibrium path for the interest rate in this economy is plotted in Figure 2 .

Thus, to the extent that an immigration reform which involves admitting 1.6 million 40-44 year old high-skilled immigrants annually is feasible, the government can choose between this reform and an income tax hike of $4.4 \%$ points. While admitting 1-2 million high-skilled immigrants conceivably could be feasible from a domestic political point of view, attracting such a large number of high-skilled middle aged immigrants might, in practice, be a bigger obstacle to feasibility. In comparison, the number of high-skilled 25-49 year old immigrants required to balance the budget is 1.8 million, or $0.70 \%$ of the population annually (simple average across age groups 25-49 in Table 2). Currently only $15.0 \%$ of the new immigrants, about 160,000 annually, are 25-49 years old and high-skilled (according to the 1990 Census $5 \%$ sample). But even though the prospects of achieving, say, an elevenfold increase of this figure seems slim, tripling or quadrupling the size of this group would still go a long way in alleviating the need for fiscal reform. 
The strong fiscal impact of immigration can be further demonstrated by considering the evolution of the debt to output ratio in the immigration reform economy, displayed in Figure 5. The debt to output ratio declines every period until 2040 and after having pursued the benchmark immigration policy for 35 years, the government debt is reduced to $6 \%$ of GNP. The government budget, excluding interest payments, is running a surplus from 1995 to 2035, while the government runs a deficit until 2000 if interest payments are included, five years more than in the fiscal reform economy.

$<$ Figure 5 about here $>$

\subsection{Net present value calculations}

An alternative way of expressing the quantitative impact of immigration on the government budget is to compute the net discounted gain to government of admitting one extra immigrant. My aim is to compute this figure under the status quo fiscal policy, so I will use the immigration reform economy as a starting point for the net present value calculations. For expositional purposes, these are partial equilibrium exercises in that I ignore potential changes in prices and bequests due to increased immigration. These general equilibrium effects will be embedded later.

Let $S(i, q, l, m, t)$ denote tax revenues minus government consumption and transfers directly incurred by an agent $(i, q, l, m)$ in period $t$. Simply computing the net present value of $\{S(i, q, l, m, t)\}_{i=m}^{I}$ is not sufficient for determining the net contribution of an immigrant, however. One must also include the cost or gain associated with potential future children, grandchildren, etc. The net discounted gain, $\operatorname{NPV}(q, l, m, t)$, including the cost of future children, of receiving one new immigrant (or native newborn) of type $(q, l, m)$ in period $t$, must then satisfy

$$
\begin{aligned}
& \operatorname{NPV}(q, l, m, t)=\sum_{i=m}^{I}(S(i, q, l, m, t+i-m)+ \\
& \left.+\phi_{i-1, q, l, m} \operatorname{NPV}(0,0,1, t+i-m)\right)\left(1+R_{t}\right) / \Pi_{j=0}^{i-m}\left(1+R_{t+j}\right)
\end{aligned}
$$

where $\phi_{m-1, q, l, m}=0$ for notational convenience. The NPV of a native newborn in period $t, \operatorname{NPV}(0,0,1, t)$, is computed by applying (31) recursively starting from steady state at $t=100$, and found to be $-\$ 88,000$. Note that a negative NPV of newborn natives can be consistent with government budget clearing because there is a sufficient number of workingage agents alive whose NPV of remaining tax revenues minus expenditures are large and positive. 


\subsection{Impact of skills}

NPV profiles across age and skills for new immigrants are displayed in Figure 6. The "skill" of an adolescent immigrant is defined as the education she will acquire in the future. Thus, the NPV of, say, a "low-skilled" adolescent immigrant is the NPV conditional on her being low-skilled her entire life.

The results reveal dramatic differences in fiscal impact across these groups: net government gain of new immigrants ranges from $-\$ 94,000$ for an infant immigrant who will remain lowskilled during her entire life, to $\$ 177,000$, or 7.0 times annual GNP per capita, for a $40-44$ year old high-skilled immigrant. Thus, denying a prospective 40-44 year old high-skilled immigrant a visa is expected to cost the government $\$ 177,000$.

$<$ Figure 6 about here $>$

Conditional on age, the NPV of high-skilled immigrants exceed the NPV of medium-skilled immigrants which, in turn, dominate the NPV of low-skilled immigrants, except for immigrants past the retirement age. In fact, the NPV of low-skilled immigrants is negative for all age groups, which explains why no positive inflow of low-skilled immigrants would suffice to balance the budget. In contrast, all high-skilled working-age immigrants yield a positive NPV.

All age profiles exhibit a strong hump-shape which peaks between 35 and 44, reflecting a trade-off between a longer remaining working life on the one hand, and a smaller number of new children on the other. The local maximum for 60-64 year old immigrants is due to the minimum requirement of ten years of Social Security contributions for receiving full benefits. Thus, 55-59 year old immigrants is the last group which can enjoy full Social Security benefits during retirement. After 65, all groups coincide (since skills by assumption distinguish immigrants on productivity only). The NPV of retired immigrants increases monotonically with age as the remaining lifetime becomes shorter.

The global maximum occurs later for high-skilled immigrants (40-44) than for mediumand low-skilled immigrants (35-39). Social Security benefits relative to tax contributions are lower for the high-skilled than for the other skill groups, so getting to the peak earnings years (40-60) more quickly becomes relatively more important than avoiding the costs associated with retirement. If the cost of children is excluded (which is equivalent to a zero fertility assumption), the peak NPV comes 5-10 years earlier for the low- and medium-skilled. Including the cost of children is of most importance for immigrants who come before they are 35 . If the cost of children was excluded, the NPV of this group would be $\$ 29,000$ higher. The timing of the peak is also influenced by the discount rate. If the sequence of individual net contributions, $\{S(i, q, l, m, t)\}_{i=m}^{I}$, is discounted at, say, 4\% (annualized) instead of the equilibrium return on capital (in Figure 2), the NPV profiles would peak at 30-34 for all skill 
groups. With a lower discount rate, the humps shift to the left since the costly retirement years are discounted to a smaller extent. Indeed, if the cost of future children is excluded, the global maximums occur, in this case, at 25-29 for the high- and medium-skilled and at 20-25 for the low-skilled.

Given the empirical age structure of new immigrants currently admitted to the US, I can compute the government gain, in net present value terms, of admitting one additional "representative" legal immigrant by weighting the age structure of current new immigrants with the net present value profiles in Figure 6 . This yields a net average gain of a mere $\$ 7,400$, which compares to NPVs of representative high-, medium-, and low-skilled immigrants of -\$36,000, - $\$ 2,000$, and $\$ 96,000$, respectively.

In contrast, the NPV of a representative illegal immigrant is $-\$ 54,000$, given the rather extreme assumptions that they incur the same government consumption as natives, pay no taxes, receive no transfers, and have the same return migration process as legal immigrants.

\subsection{General equilibrium effects in the NPV analysis}

Incorporating general equilibrium effects of immigration would be likely to reduce the net benefit of immigrants. If immigration is not associated with a capital inflow (as I have assumed here), an increase in immigration tends to raise the capital to output ratio which makes the interest rate increase and reduces wages for all agents. Recall that these effects might be expected to work against immigrants, since the cost of servicing the public debt would rise, and tax revenues fall because most tax revenues are collected from labor under the US tax system. Even if changes in prices were extremely small, the total impact on the government budget would not necessarily be negligible since the price effects apply to the entire population.

The general equilbrium effects are manifested in that some groups of immigrants, e.g. the 20-24 year old medium-skilled, have a positive NPV, even though the future fiscal problems cannot be resolved by admitting a positive number of these immigrants. To quantify the importance of general equilibrium effects in a more direct way, I compare the above net present value calculations with a present value calculation in which prices and bequests do move in response to an inflow of new immigrants. The methodology is described by the following experiment, using, say, the immigration policy reform economy as a starting point: ${ }^{6}$

1. Admit one additional legal high-skilled 40-44 year old immigrant during the first period and revert to the benchmark immigration policy thereafter (in absolute numbers).

\footnotetext{
${ }^{6}$ Note that if the budget, in addition to admitting a large number of immigrants, was balanced partially through a tax hike and/or by spending cuts, the net gain would be larger so the calculation at hand could be interpreted as a lower bound on the net government gain of new immigrants.
} 
2. Measure by how much the government debt could be increased (decreased), relative to the benchmark policy, and still balance the budget in the long run. This change is equivalent to the discounted net government gain (loss) of admitting a 40-44 year old high-skilled immigrant. The perturbation in public debt is assumed to be redistributed in a lump sum fashion.

I found the results to be substantially different from the partial equilibrium case: the net gain per 40-44 year old high-skilled immigrant decreased to $\$ 123,000$, a reduction of $31 \%$ relative to the partial equilibrium exercise.

\subsection{The role of return migration}

Return migration is a central part of the demographic process, and, to the extent that public policy can influence return migration, one would like to understand its impact on public coffers. To this end, I contrast the benchmark return migration process to a case of no return migration. The NPV profiles for high-skilled immigrants, displayed in Figure 7, reveal that reducing return migration to zero would increase the NPV of 5-49 year old immigrants and lower the NPV for others. The calibrated return migration process implies substantial emigration after the first (five-year) period. Thus, groups which (in the near future) face a long sequence of positive (negative) contributions to government should see their NPV increase (decrease) if return migration is lowered. Indeed, all immigrants over 50 do retire within 15 years. Moreover, the peak of the NPV profile shifts to the left from $40-44$ to $35-39$ years old when return migration is removed as the 35-39 years old have a longer remaining working life than the 40-44 year old immigrants.

This picture is mirrored for the calculations regarding the flows of immigrants required to balance the budget, see row 8 of Table 2. A smaller number of new immigrants are required for all age groups between 20-49, while a slightly larger number are needed for the 50-54 year old high-skilled immigrants.

$<$ Figure 7 about here $>$

\subsection{The role of family migration}

Admitting adult immigrants but excluding their (already existing) children may not be

politically feasible. To understand the impact of family migration, I contrast the benchmark single immigrants case with a case where immigrants bring children who are 15 years old or younger and leave their older children behind. The children are assumed to be mediumskilled, and the distribution of an immigrant's children is computed, conditional on her age, 
by assuming pre-migration fertility rates to be a fixed fraction of native fertility, where this fraction is set so that the inflow of immigrants under 15 match the data.

The dashed line in Figure 7 illustrate the effect of family unit migration on the NPV profile of high-skilled immigrants. The numbers denote NPV per head of household, including the children brought from abroad. The effects are considerable; the NPV of 20-50 year old immigrants decreases by $\$ 37,000$ relative to the single immigrant case. The impact is largest for 30-39 year old immigrants, whose NPV is reduced by $\$ 56,000$, on average. This is because these families have the largest number of children under 15 , on average 1.53 per adult family member according to my calculations.

This picture is largely confirmed when considering the lowest number of immigrants (including children) required for balancing the budget: the minimum number of immigrants required increases to $1.08 \%$ of the population annually, The head of the family is then assumed to be 40-49 years old and high-skilled (see row 5 of Table 2).

\subsection{Static accounting exercises}

Several studies analyze the public cost or gain from immigration in a static accounting framework by computing the government surplus in one particular year of all immigrants currently residing in the US. Borjas (1994), Huddle (1994) and Passel (1994) quantify the net government gain on immigration in 1993 to $-\$ 16$ billion, $-\$ 40$ billion, and $\$ 27$ billion, respectively. To contrast my findings to these previous studies, I perform a similar exercise with my model. I consider the current fiscal policy and the current immigration policy, disregarding that this combination is infeasible, and using the price sequence of the immigration policy reform experiment. I then compute the net government surplus in the first period, resembling the 1993-1997 period, to be about $0.32 \%$ of GNP, or $\$ 21$ billion in 1993 , which is within the range of the previous studies. This figure includes the government consumption incurred by illegal immigrants. If illegal immigrants are excluded, the 1993 gain increases to $\$ 33$ billion, according to the model.

Note, however, that the current age distribution of immigrants is favorable, since the surge in immigration is a recent phenomenon. If the static accounting exercise is performed for future periods (again, under the current immigration and fiscal policies), it will produce negative numbers for legal immigrants after 11 periods (55 years).

\subsection{Sensitivity analysis}

To check the sensitivity of the absence of public goods assumption, I assume, alternatively, that part of government consumption provides a nonrival public good and that future public 
goods expenditures, in levels, is a fixed fraction of government consumption in the fiscal reform economy. Thus, additional immigrants do not increase the public goods provision, and the immigrants' net contributions, $S(i, q, l, m, t)$, are increased accordingly. I set the fraction of public goods in government consumption to 31\%, which equals the 1990-94 share of national defense, foreign affairs, and general science, space and technology in government purchases of goods and services. Moreover, agents' preferences are assumed to be additively separable over the public good on the one hand, and the standard private consumptionleisure composite on the other, so that the provision of public goods does not affect the agents' decisions. In this case, the NPV of new immigrants increase by a substantial $\$ 19,000$ on average; the younger the immigrants the larger the increase ( $\$ 21,000$ for $0-4$ years old).

The benchmark calibration implies a life expectancy at birth of 77 years. The SSA population projections, for instance, assume life expectancy to increase gradually and reach 82 years by 2075. To explore how sensitive the results are to the mortality assumptions, I study an extreme case where life expectancy is 82 years from period one. Under this demographic scenario, the implied dependency ratios exceed the SSA projections until 2050 and reaches a maximum of 0.399 in 2035. The income tax hike and inflow of 40-44 year old high skilled immigrants required to balance the budget are in this case $5.6 \%$ and $0.80 \%$, respectively, compared to $4.4 \%$ and $0.62 \%$ under the benchmark mortality assumptions. The impact on the NPV profiles are qualitatively similar to the case of zero return migration, albeit with generally smaller quantitative magnitudes.

As discussed in Section 5.5, the initial wealth to output ratio (3.8) is considerably higher than the steady state wealth to output ratio of 2.0. In order to understand the impact of the initial capital stock and steady state wealth level, I experiment with two alternative specifications:

1. reduce the initial capital stock such that the initial capital output ratio is 2.5 , in which case agents initially hold $16 \%$ more wealth than in steady state.

2. increase the discount factor, $\beta$, to 1.037 such that steady state capital to output ratio is 3.3 . In this case agents hold $24 \%$ more wealth than in steady state.

The results are quite robust to the initial capital stock. When the initial capital to output ratio is 2.5 , the smallest number of high-skilled 40-44 year old immigrants required to balance the budget nudges down to $0.61 \%$ of the population annually. A lower initial capital stock implies a smaller initial GNP and, in turn, permanently lower government expenditures compared to the benchmark calibration. Thus, less initial capital can require a smaller immigration reform the way I have calibrated the economy. As the interest rate is generally higher than in the benchmark calibration, the NPV of a representative new immigrant falls by $\$ 14,500$. In contrast, the higher discount factor experiment implies large changes in the results: the smallest number of high-skilled 40-44 year old immigrants required to balance 
the budget is reduced by half to $0.30 \%$, while the NPV of a representative new immigrant increases by $\$ 28,300$.

All results are sensitive to the wage income of immigrants. To illustrate this, I explore the case where immigrants earn $10 \%$ less than in the benchmark case, which reduces the net benefits of immigration significantly. For example, the NPV of 40-44 year old high-skilled immigrants falls by about one sixth, or $\$ 31,000$, and the NPV of a representative immigrant falls to $-\$ 6,000$. The minimum number of new high-skilled immigrants required to balance the budget increases with about $29 \%$ to $0.80 \%$ of the population (see row 6 in Table 2).

The NPV of immigrants is negatively related to fertility, since newborn children have a negative NPV. To check the sensitivity of the calibration, I experiment with $10 \%$ higher fertility rates for high-skilled immigrants. The impact on the lowest number of immigrants required to balance the budget is negligible for immigrants over 25. For 20-24 year old immigrants, the increase is a modest $11 \%$ points, see row 7 in Table 2.

In equilibrium few agents end up with a positive tax on their social security benefits. Moreover, the quantitative results are quite robust to the specification of taxation of benefits. To show this, I carried out an experiment where all retirees pay a tax $0.25 \tau$ on all social security benefits, substantially more than the average level of taxation implied under $\vartheta($.$) . In this$ case, the NPV profiles hardly move: the maximum change is a $\$ 5,000$ increase in NPV for 60-64 year old immigrants. Moreover, the minimum number of high-skilled 40-44 year old immigrants required to balance the budget nudges up from $0.62 \%$ to $0.64 \%$ of the population annually. A higher tax on benefits might require a slightly larger immigration reform since the calibrated income tax rate $\tau$ is $0.6 \%$ points lower in this case (to ensure that total initial tax revenues equal $32.5 \%$ of GNP).

\section{Conclusion}

The paper demonstrates that immigration policy has strong quantitative implications for fiscal policy, and argues that the immigration policy should be viewed as an important determinant of government revenues. In particular, a case is made that skills and age at the time of arrival are of considerable importance for the cost-benefit calculation of new immigrants.

To illuminate the quantitative fiscal implications of immigration, I pursue two strategies: First, I investigate if an immigration policy reform alone could resolve the fiscal problems associated with the ageing of the baby boom generation. Second, I compute the net government gain, in present value terms, of admitting one additional immigrant to the US, conditional on age and skills at the time of immigration.

Using a calibrated general equilibrium overlapping generations model, which explicitly ac- 
counts for key differences between immigrants and natives, Social Security and the demographic transition, I find that immigration policies that sustain the current fiscal policy do exist and are characterized by increased inflows of middle aged high- and medium-skilled immigrants. Admittedly, the American public seems opposed to such large increases in immigration. However, when faced with the trade-off between higher taxes on the one hand and a larger number of high-skilled immigrants on the other, it seems likely that a majority would, on the margin, opt for increasing the number of immigrants.

Moreover, the analysis suggests that the discounted net government gain varies considerably across age and skills of new immigrants, with large and positive figures for high- and mediumskilled working-age immigrants. Thus, rather than viewing immigration as a problem, the perspective should be one of seeing high- and middle-skilled immigrants as an attractive resource, for which various countries compete. To the extent that one is willing to consider using the immigration policy for enriching public coffers, the immigration policy should involve attempts to actively attracting high-skilled immigrants, rather than playing its current passive door-keeper role. To this end, the paper offers clear directions for which groups of immigrants to target.

This analysis has described how some of the migration rent benefits natives via the government. The government could, however, get a larger share if it was willing to deviate from the principle of taxing natives and legal immigrants at the same rates, although such reforms would have to be traded off against the reduced attractiveness of the US as a host country.

There has been a recent debate on the desirability of limiting immigration in border states such as California, Texas, and Florida. These states shoulder a significant part of the cost of immigration without necessarily receiving the offsetting benefits, and immigrants in general are perceived as a net financial burden on state and local government. My analysis does not consider if this view is valid, since I address public finance on an aggregate level, although my results do indicate that some groups, in particular low-skilled and illegal immigrants, represent big costs for the overall government. 


\section{References}

Aaron, H., B. Bosworth, \& G. Burtless, (1989), Can America Afford to Grow Old? Paying for Social Security, The Brooking Institution, Washington D.C.

Akbari, A. H., (1989), The benefits of immigration to Canada: Evidence on tax and public services, Canadian Public Policy 15.

Auerbach, A. J. \& L. J. Kotlikoff, (1987), Dynamic Fiscal Policy, Cambridge University Press, Cambridge.

Auerbach, A. J., L. J. Kotlikoff, R. P. Hagemann, \& G. Nicoletti, (1989), The economic dynamics of an ageing population: the case of four OECD countries, OECD Economic Studies 12, 97-130.

Baker, M. \& D. Benjamin, (1995), The receipt of transfer payments by immigrants in Canada, Journal of Human Resources XXX, 650-676.

Bell, F. C., (1997), Social Security Area Population Projections: 1997, Social Security Administration, Actuarial Study No. 112, SSA Pub. No. 11-11553.

Bonin, H., B. Raffelhüschen, \& J. Walliser, (1997), Can immigration alleviate the demographic burden?, Working paper no. 0797, University of Bergen.

Borjas, G. J., (1990), Friends or Strangers, Basic Books, New York.

Borjas, G. J., (1994), The economics of immigration, Journal of Economic Literature 32, 1667-1717.

Borjas, G. J. \& B. Bratsberg, (1996), Who leaves? The outmigration of the foreign-born, The Review of Economics and Statistics 78, 165-176.

Borjas, G. J. \& L. Hilton, (1996), Immigration and the welfare state: Immigrant participation in meanstested entitlement programs, Quarterly Journal of Economics 11, 575-604.

Cooley, T. F. \& E. C. Prescott, (1995), Economic Growth and Business Cycles, chapter 1, 1-38, Princeton University Press, New Jersey, In Frontiers of Business Cycle Research, T. Cooley, editor.

Fix, M. \& J. Passel, (1994), Immigration and immigrants - setting the record straight, Program for research on immigration policy, Urban Institute, Washington D.C.

Fix, M., J. S. Passel, \& W. Zimmermann, (1996), The use of SSI and other welfare programs by immigrants, Testimony before the House of Representatives Ways and Means Committee.

Friedberg, R. M., (1993), The labor market assimilation of immigrants: the role of age at arrival, Unpublished Manuscript, Brown University.

Huddle, D., (1994), The Net National Cost of Immigration, Carrying Capacity Network, Washington D.C.

Hurd, M. A., (1989), Mortality risks and bequests, Econometrica 57, 173-209.

Jasso, G. \& M. R. Rosenzweig, (1982), Estimating the emigration rates of legal immigrants using administrative and survey data: the 1971 cohort of immigrants to the United States, Demography 19, 279-290.

Lee, R. D., (1974), Forecasting births in post-transition populations: Stochastic renewal with serially correlated fertility, Journal of the American Statistical Association 69, 607-17.

Passel, J., (1994), Immigrants and taxes: a reappraisal of Huddle's The Cost of Immigrants, Program for Research on Immigration Policy 29, Urban Institute, Washington D.C.

Ríos-Rull, J.-V., (1992), Population changes and capital accumulation: The aging of the baby boom, Unpublished Manuscript, Carnegie-Mellon University. 
Ríos-Rull, J.-V., (1996), Life cycle economies and aggregate fluctuations, Review of Economic Studies 63, $465-489$.

Simon, J. L., (1984), Immigrants, taxes and welfare in the United States, Population and Development Review 10, 55-69.

Storesletten, K., (1995), What is an Immigrant?, chapter 1, In On the Economics of Immigration Carnegie Mellon University Ph.D. Thesis.

U.S. Bureau of the Census, (1996), US population estimates, by age, sex, race, and hispanic origin: 1996, Technical report, US Bureau of the Census, Washington D.C., Current Population Reports, P25-1130.

Warren, R. \& J. M. Peck, (1980), Foreign-born emigration from the United States: 1960 to 1970, Demography $17,71-81$. 


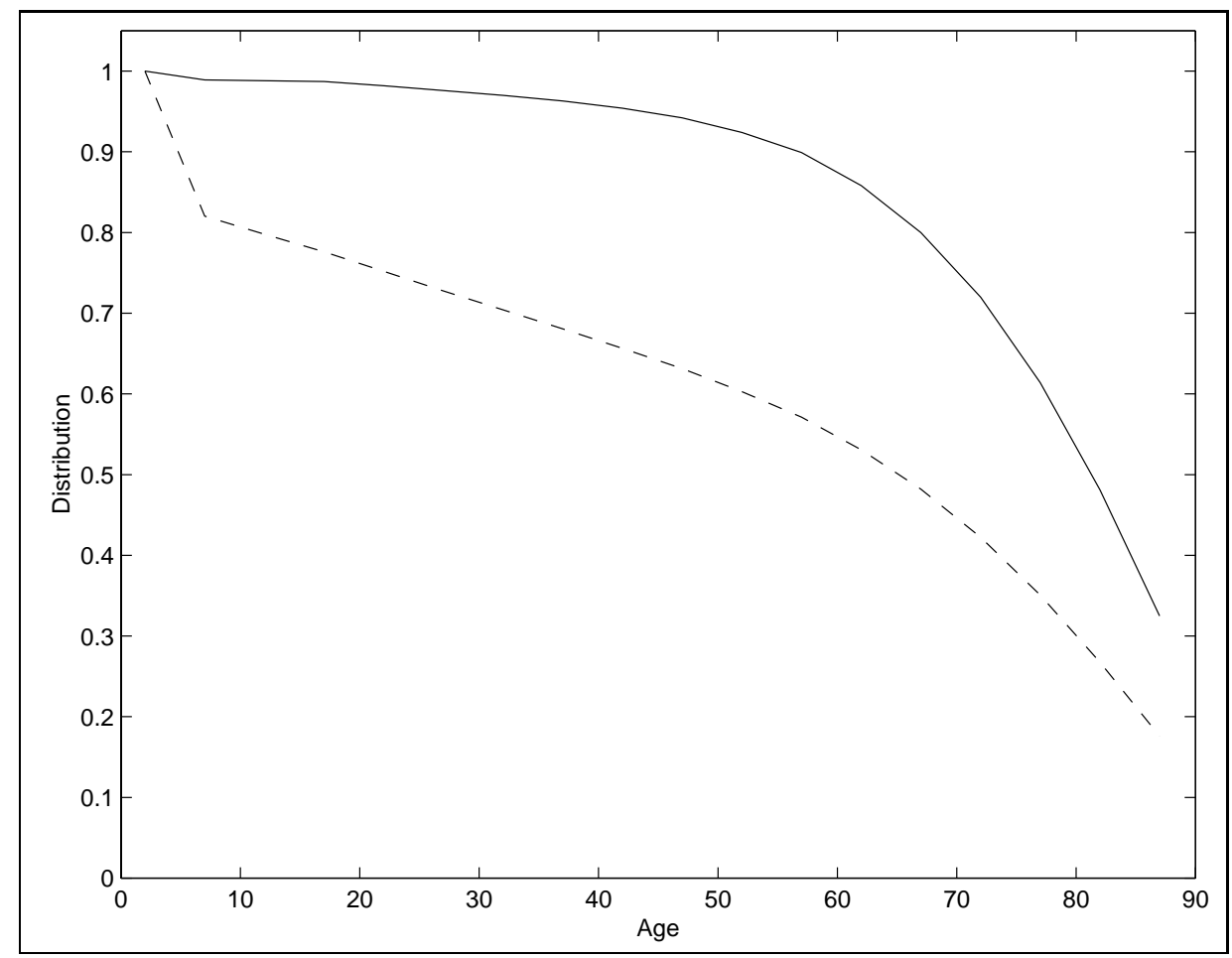

Figure 1: The impact of return migration: the lower (dashed) graph is the evolution of a cohort of immigrants (who arrive when one year old) under the calibrated return migration process, while the upper (solid) graph is the evolution if the cohort experiences zero return migration. 


\begin{tabular}{|c|c|c|}
\hline $\begin{array}{l}\text { Population } \\
\text { Return } \\
\text { migration }\end{array}$ & $\begin{array}{c}\text { Mortality } \\
\text { Fertility } \\
\rho_{1} \\
\rho_{2} \\
\eta_{1} \\
\eta_{i}, i>1 \\
\text { Time period } \\
\zeta\end{array}$ & $\begin{array}{c}1988 \text { U.S. level } \\
\text { AR(2) process } \\
1.28 \\
-0.65 \\
0.171 \% \\
0.026 \% \\
5 \text { years } \\
5 \text { (20-25 years old) }\end{array}$ \\
\hline Preferences & $\begin{array}{l}\alpha \\
\gamma \\
\beta\end{array}$ & $\begin{array}{c}0.33 \\
4 \\
1.011 \text { (annualized) }\end{array}$ \\
\hline Technology & $\begin{array}{l}\theta \\
\delta \\
\Gamma\end{array}$ & $\begin{array}{c}0.4 \\
4.8 \% \\
1.5 \% \text { (annualized) }\end{array}$ \\
\hline Government & $\begin{array}{c}\tau \\
\tau_{s} \\
g_{1-5} \\
g_{6-13} \\
g_{14+} \\
\xi_{1-4} \\
\xi_{5-12} \\
\xi_{13} \\
\xi_{14} \\
\xi_{15} \\
\xi_{16} \\
\xi_{17+} \\
\varkappa\end{array}$ & $\begin{array}{c}28.2 \% \\
15.3 \% \\
20.6 \% \text { of } Y_{0} \\
11.3 \% \text { of } Y_{0} \\
19.5 \% \text { of } Y_{0} \\
7.8 \% \text { of } Y_{0} \\
8.1 \% \text { of } Y_{0} \\
11.8 \% \text { of } Y_{0} \\
18.4 \% \text { of } Y_{0} \\
22.7 \% \text { of } Y_{0} \\
27.9 \% \text { of } Y_{0} \\
37.4 \% \text { of } Y_{0} \\
0.25\end{array}$ \\
\hline $\begin{array}{l}\text { Initial } \\
\text { conditions }\end{array}$ & $\begin{array}{c}\text { Population distribution } \\
\text { debt-output ratio } \\
\text { capital-output ratio }\end{array}$ & $\begin{array}{c}1990 \text { Census } \\
50 \% \\
3.3\end{array}$ \\
\hline
\end{tabular}

Table 1: Key parameter choices. $Y_{0}$ refers to output per capita in the initial period in the fiscal reform economy. 


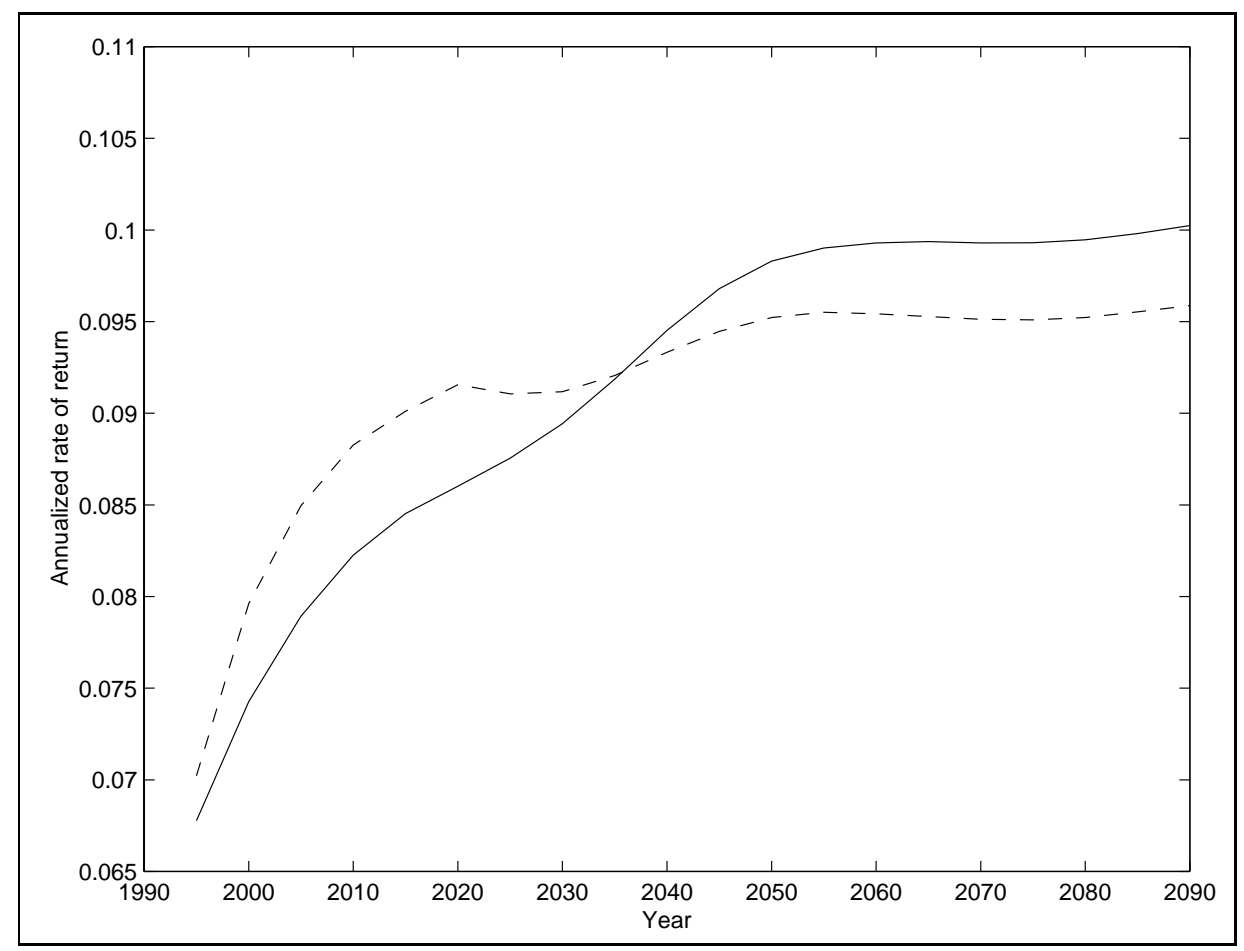

Figure 2: Projected rates of return on capital in the fiscal reform economy (solid line) and the immigration reform economy (dashed line).

\begin{tabular}{|l|c|c|c|c|c|c|c|}
\hline Experiment & \multicolumn{9}{|c|}{ Age of new immigrants: } \\
& $20-24$ & $25-29$ & $30-34$ & $35-39$ & $40-44$ & $45-49$ & $50-54$ \\
\hline Baseline (high skilled) & 1.89 & 0.84 & 0.66 & 0.62 & 0.62 & 0.77 & 2.01 \\
Medium skilled & - & 3.13 & 2.01 & 1.79 & 2.13 & 3.86 & - \\
Low skilled & - & - & - & - & - & - & - \\
Averaged over skills & - & 2.23 & 1.50 & 1.40 & 1.67 & 3.61 & - \\
Family unit & 4.20 & 2.06 & 2.02 & 1.57 & 1.10 & 1.08 & 2.06 \\
Low earnings & - & 1.20 & 0.90 & 0.80 & 0.80 & 1.10 & 3.52 \\
High fertility & 2.00 & 0.88 & 0.68 & 0.63 & 0.62 & 0.77 & 2.01 \\
No return migration & 1.17 & 0.65 & 0.54 & 0.50 & 0.53 & 0.74 & 2.43 \\
\hline
\end{tabular}

Table 2: Annual immigration (in percent of population) required to balance the government budget if the fiscal policy is kept unchanged. A dash - means that no positive number of immigrants was large enough to balance the budget in the long run. 


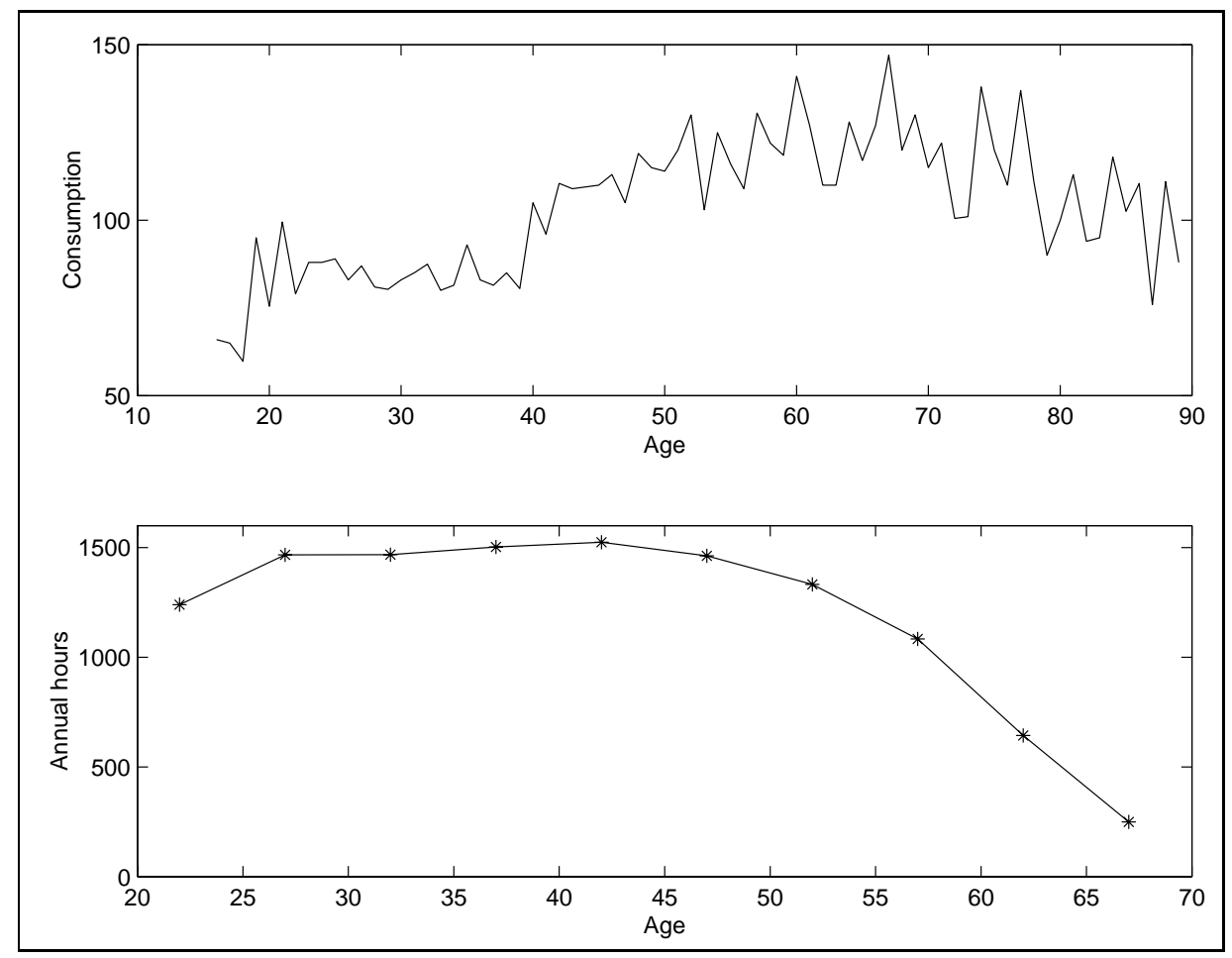

Figure 3: Empirical age profiles of consumption and work effort. The upper panel is consumption per household member (source: Current Expenditure Survey 1990, reproduced from Ríos-Rull (1997)). The lower panel shows the average annual hours worked per individual (source: $5 \%$ sample of 1990 Census). 


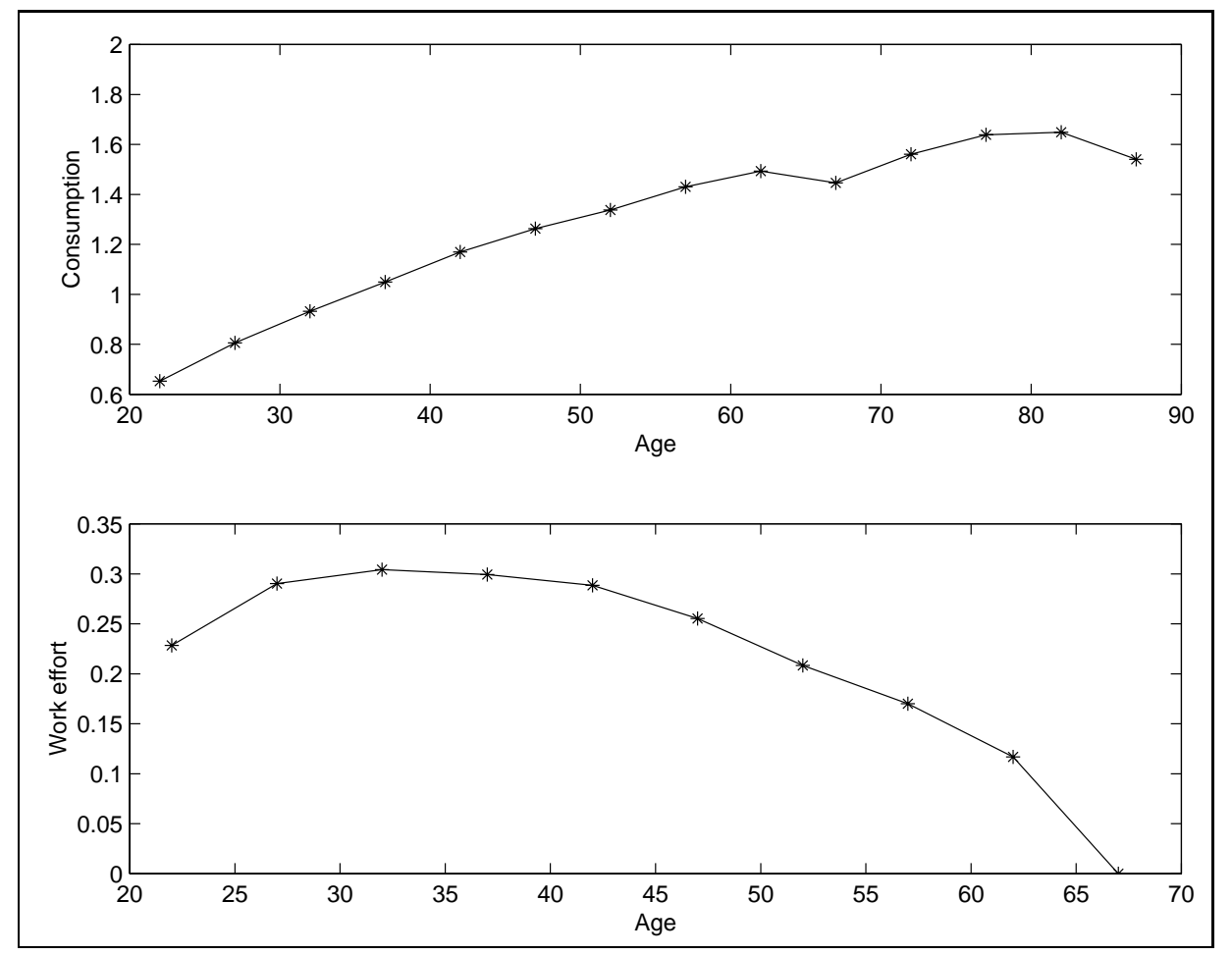

Figure 4: Steady state age profiles of consumption (upper panel) and work effort (lower panel) in the fiscal reform economy. 


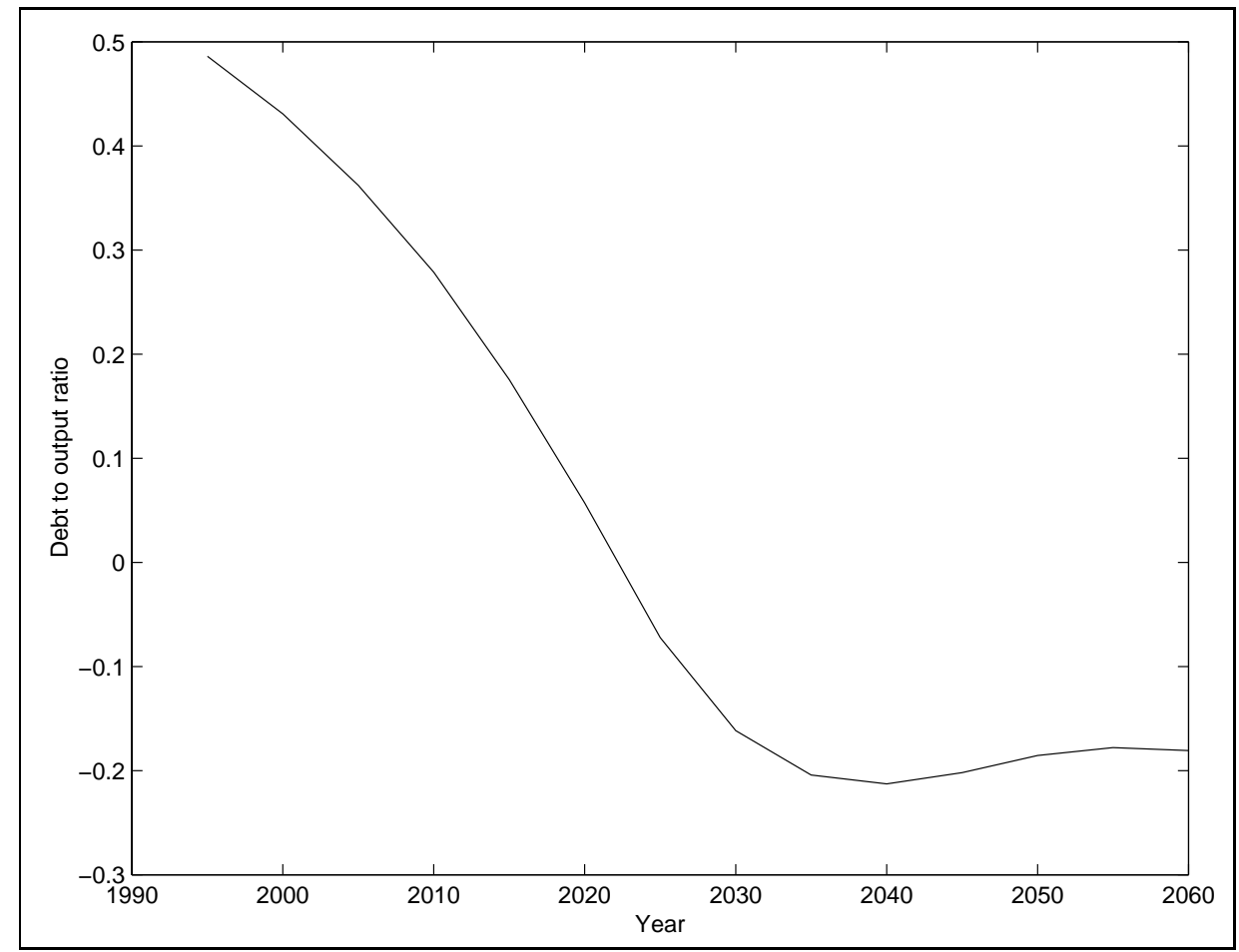

Figure 5: Projected future debt to output ratio in the immigration reform economy. 


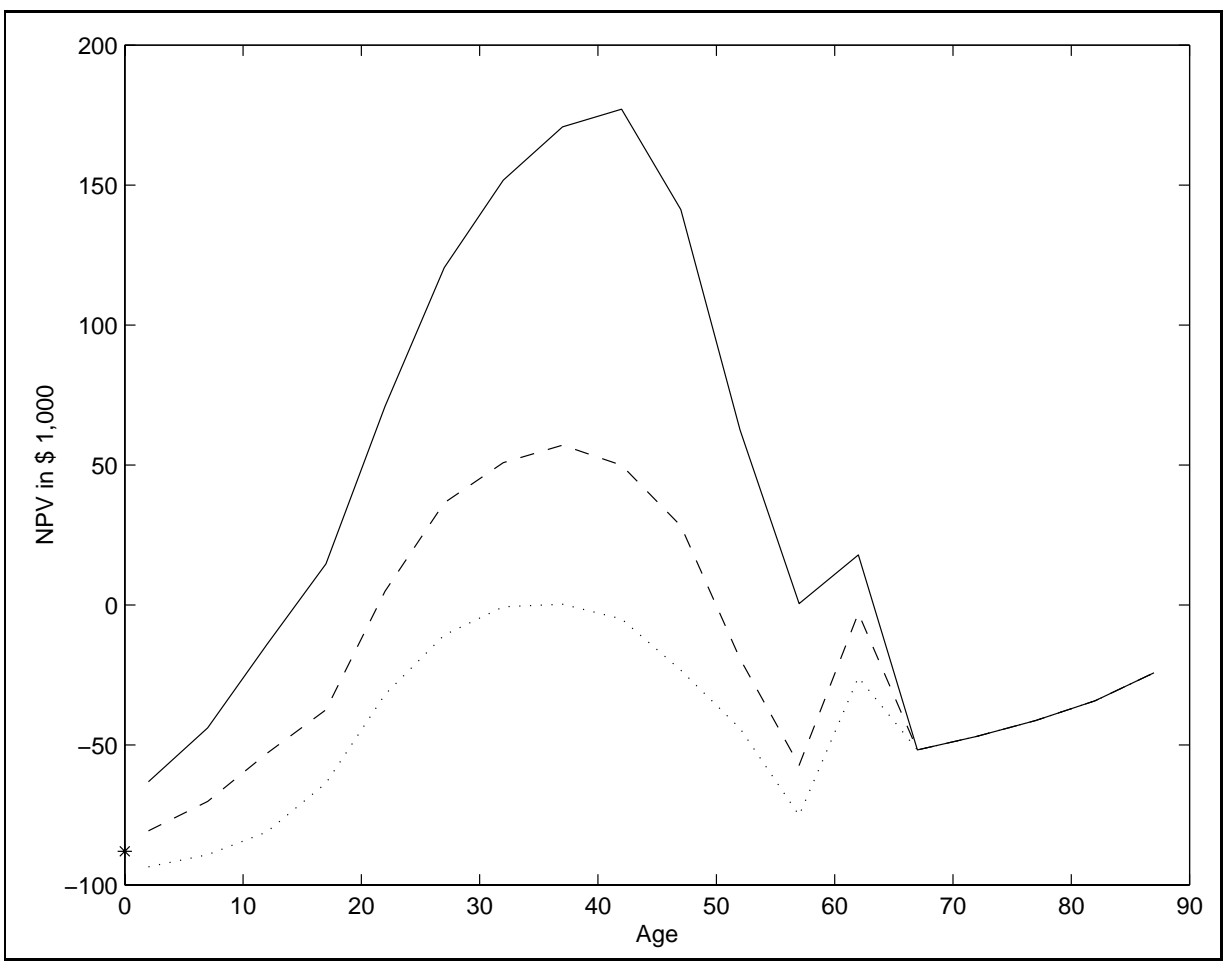

Figure 6: Discounted net public gain of admitting additional immigrants. The upper graph is high-skilled immigrants (the benchmark case), the middle graph is medium-skilled immigrants, and the lower graph refers to low-skilled immigrants. Net public gain of newborn natives is marked by a ${ }^{*}$ on the $y$-axis. All results are partial equilibrium calculations, with the prices and fiscal policy of the immigration reform economy, and are reported in 1993 dollars. 


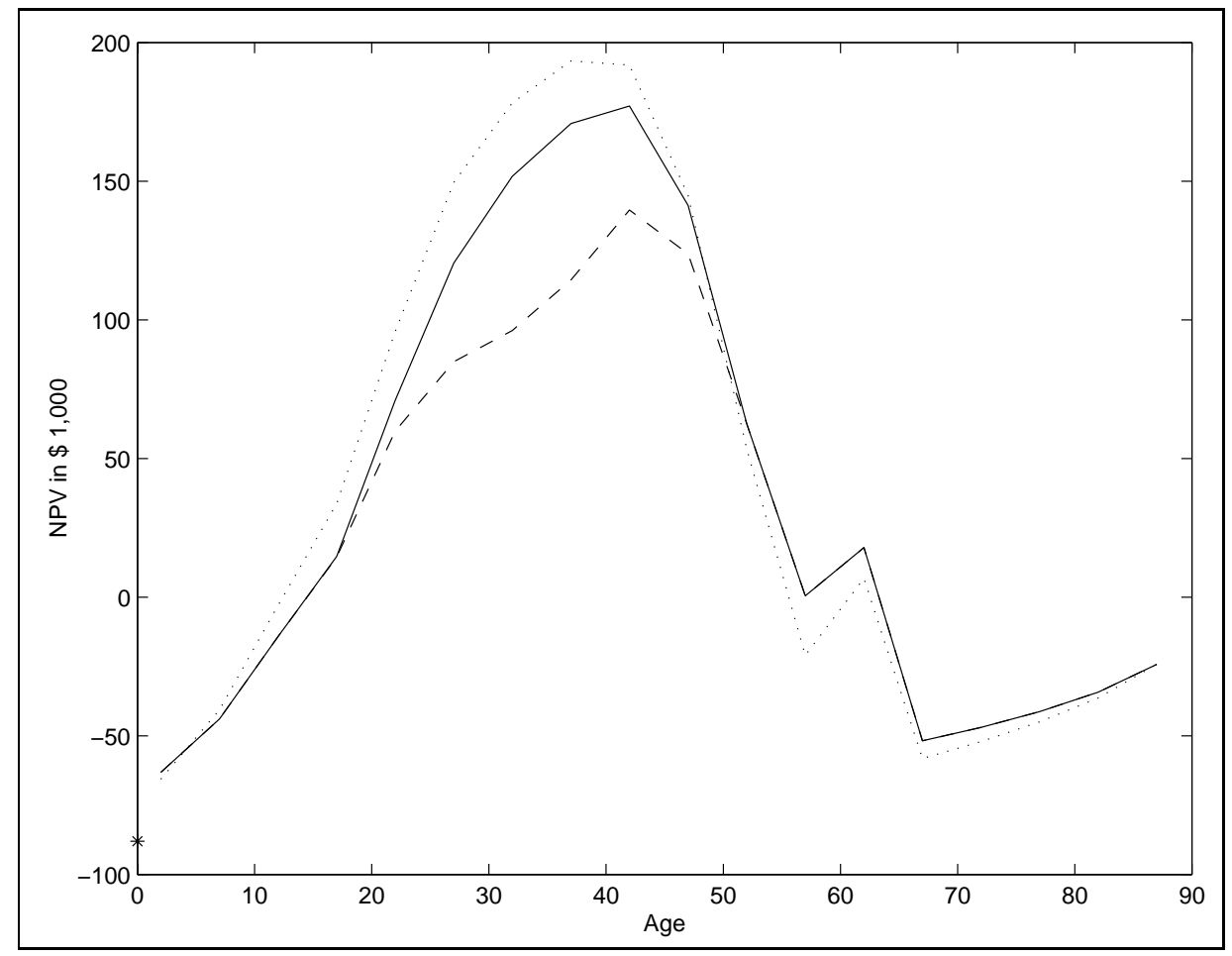

Figure 7: Discounted net public gain of admitting additional immigrants. The solid graph refers to high-skilled immigrants (the benchmark case). The dotted line is net public gain of high-skilled immigrants if there is no return migration, while the dashed line is the average net public gain per head of household if immigrants are admitted in family units and bring children who are 15 years old or younger ("age" on the x-axis denotes the age of the head household). Net public gain of newborn natives is marked by a ${ }^{*}$ on the $y$-axis. All results are partial equilibrium calculations, with the prices and fiscal policy of the immigration reform economy, and are reported in 1993 dollars. 